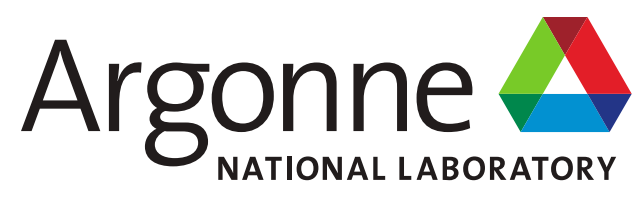

\title{
Massachusetts Institute of Technology Reactor LEU Fuel Element Flow Test Conceptual Design - Hydraulic Reactor Design Parameters
}

Nuclear Science \& Engineering Division 


\title{
About Argonne National Laboratory
}

Argonne is a U.S. Department of Energy laboratory managed by UChicago Argonne, LLC under contract DE-AC02-06CH11357. The Laboratory's main facility is outside Chicago, at 9700 South Cass Avenue, Argonne, Illinois 60439. For information about Argonne and its pioneering science and technology programs, see www.anl.gov.

\section{DOCUMENT AVAILABILITY}

Online Access: U.S. Department of Energy (DOE) reports produced after 1991 and a growing number of pre-1991 documents are available free at OSTI.GOV (http://www.osti.gov/), a service of the U.S. Dept. of Energy's Office of Scientific and Technical Information.

\author{
Reports not in digital format may be purchased by the public from the \\ National Technical Information Service (NTIS): \\ U.S. Department of Commerce \\ National Technical Information Service \\ 5301 Shawnee Rd \\ Alexandria, VA 22312 \\ www.ntis.gov \\ Phone: (800) 553-NTIS (6847) or (703) \\ 605-6000 Fax: (703) 605-6900 \\ Email: orders@ntis.gov
}

\section{Reports not in digital format are available to DOE and DOE contractors from the Office of Scientific and Technical Information (OSTI):}

U.S. Department of Energy

Office of Scientific and Technical Information

P.O. Box 62

Oak Ridge, TN 37831-0062

www.osti.gov

Phone: (865) 576-8401

Fax: (865) 576-5728

Email: reports@osti.gov

Disclaimer

\section{Disclaimer}

This report was prepared as an account of work sponsored by an agency of the United States Government. Neither the United States Government nor any agency thereof, nor UChicago Argonne, LLC, nor any of their employees or officers, makes any warranty, express or implied, or assumes any legal liability or responsibility for the accuracy, completeness, or usefulness of any information, apparatus, product, or process disclosed, or represents that its use would not infringe privately owned rights. Reference herein to any specific commercial product, process, or service by trade name, trademark, manufacturer, or otherwise, does not necessarily constitute or imply its endorsement, recommendation, or favoring by the United States Government or any agency thereof. The views and opinions of document authors expressed herein do not necessarily state or reflect those of the United States Government or any agency thereof, Argonne National Laboratory, or UChicago Argonne, LLC. 


\section{Massachusetts Institute of Technology Reactor LEU Fuel Element Flow Test Conceptual Design - Hydraulic Reactor Design Parameters}

prepared by

Guanyi Wang, Cezary Bojanowski, Andrew Hebden, David Jaluvka, Erik Wilson Nuclear Science \& Engineering Division, Argonne National Laboratory

Lin-wen Hu

Nuclear Reactor Laboratory, Massachusetts Institute of Technology

August 2021 
(This page left intentionally blank) 


\section{Acronyms and Abbreviations}

FQ

HEU

HMFTF

LEU

LSSS

$\mathrm{M}^{3}$

MIT

MITR

NNSA

OSU

$\mathrm{RC}$

SAR

SME

U-10Mo

USHPRR fuel qualification

highly enriched uranium with $\geq 20 \mathrm{wt} \%{ }^{235} \mathrm{U}$ enrichment

Hydro-Mechanical Fuel Testing Facility

low-enriched uranium with $<20 \mathrm{wt} \%$ 235U enrichment

limiting safety system setting

NNSA Office of Material Management and Minimization

Massachusetts Institute of Technology

Massachusetts Institute of Technology Research Reactor

U.S. National Nuclear Security Administration

Oregon State University

reactor conversion

Safety Analysis Report

subject matter expert

uranium - 10 wt\% molybdenum monolithic alloy fuel

U.S. high-performance research reactor 


\section{Definition of Terms}

\begin{tabular}{|c|c|}
\hline Best estimate & $\begin{array}{l}\text { Parameter value that is determined with the best available methods } \\
\text { and/or models without including uncertainty. }\end{array}$ \\
\hline Bounding & $\begin{array}{l}\text { A parameter value that has been technically determined to not be } \\
\text { exceeded under given conditions, such as, for example, normal operating } \\
\text { conditions. }\end{array}$ \\
\hline Conservative & $\begin{array}{l}\text { Method, or resulting parameter value, that is not best estimate and } \\
\text { includes uncertainty or margin whether discretionary or due to } \\
\text { conservative assumptions. }\end{array}$ \\
\hline Fuel core & The uranium-bearing region of each fuel plate. \\
\hline Fuel qualification & $\begin{array}{l}\text { The process of designing, conducting, and evaluating experiments to } \\
\text { ensure that the fuel is capable of performing without failure during } \\
\text { reactor operations up to reported performance limits. Fuel qualification } \\
\text { also includes measurements and reporting of fuel properties that can be } \\
\text { used in performance and safety modeling. }\end{array}$ \\
\hline Licensed power & $\begin{array}{l}\text { The power approved by the regulatory authority up to which the reactor } \\
\text { licensed to operate. For a reactor without a defined licensed duration, } \\
\text { this term is taken to be the equivalent of approved operating power. }\end{array}$ \\
\hline $\begin{array}{l}\text { Limiting safety } \\
\text { system settings }\end{array}$ & $\begin{array}{l}\text { Limiting values for settings of the safety channels by which point } \\
\text { protective action must be initiated. The LSSSs are chosen so that } \\
\text { automatic protective action terminates the abnormal situation before a } \\
\text { safety limit is reached. The calculation of the LSSS shall include the } \\
\text { process uncertainty, the overall measurement uncertainty, and transient } \\
\text { phenomena of the process instrumentation. }\end{array}$ \\
\hline Nominal & Value of a parameter under normal operating conditions. \\
\hline $\begin{array}{l}\text { Normal operating } \\
\text { conditions }\end{array}$ & $\begin{array}{l}\text { Conditions that are reasonably expected to occur up to and including at } \\
\text { the reactor licensed power. These do not include calculation or } \\
\text { measurement uncertainties. }\end{array}$ \\
\hline $\begin{array}{l}\text { Prototypic } \\
\text { conditions }\end{array}$ & $\begin{array}{l}\text { Conditions that are considered representative of normal operating } \\
\text { conditions and matching key aspects of the fuel design geometry. }\end{array}$ \\
\hline $\begin{array}{l}\text { Reactor design } \\
\text { parameter }\end{array}$ & $\begin{array}{l}\text { Best estimate value from reactor analysis used as a basis in experiment } \\
\text { design for fuel qualification and licensing tests. Each reactor stakeholder } \\
\text { in RC Pillar activities identifies and documents reactor design parameter } \\
\text { values. }\end{array}$ \\
\hline Regime appropriate & $\begin{array}{l}\text { A set of conditions representative of reactor operations for which the } \\
\text { value(s) does not have an impact on phenomena within a known range. } \\
\text { For example, irradiation-induced creep in U-10Mo fuel at USHPRR } \\
\text { operating conditions is not correlated to temperature, and therefore } \\
\text { temperatures at which thermally induced creep does not occur can be } \\
\text { referred to as "regime appropriate." }\end{array}$ \\
\hline Safety basis & $\begin{array}{l}\text { A SAR, referenced supporting information, and other regulatory } \\
\text { materials that provide the basis for safe operation of a reactor facility. }\end{array}$ \\
\hline Target test value & $\begin{array}{l}\text { The goal value based on a reactor design parameter to be achieved } \\
\text { during testing, such as during an irradiation experiment to support fuel } \\
\text { qualification or fuel demonstration. The FQ, or other, Pillar identifies and } \\
\text { documents target test values in collaboration with other Pillars based on } \\
\text { the reactor design parameters. }\end{array}$ \\
\hline
\end{tabular}

Massachusetts Institute of Technology Reactor LEU Fuel Element Flow Test Conceptual Design - Hydraulic Reactor Design Parameters 


\section{Executive Summary}

The Massachusetts Institute of Technology Reactor (MITR-II, also referred to as MITR) is one of six U.S. high performance research reactors (USHPRR), including one critical facility, that is actively collaborating with the U.S. National Nuclear Security Administration (NNSA) Material Management and Minimization $\left(\mathrm{M}^{3}\right)$ Reactor Conversion Program to convert to the use of low-enriched uranium (LEU, < $20 \mathrm{wt} \%{ }^{235 \mathrm{U}}$ ) fuel. The MIT Nuclear Reactor Laboratory has been working with the USHPRR Reactor Conversion (RC) Pillar at Argonne National Laboratory to perform fuel element design and fuel cycle performance analyses, steady-state thermal hydraulics safety analyses, and accident safety analyses in preparation for the conversion of MITR and support a preliminary Safety Analysis Report (SAR) for conversion to LEU fuel.

This work is a part of the hydraulic performance evaluation conducted by USHPRR RC Pillar. The purpose of the hydraulic performance evaluation of the MITR LEU fuel element designed by the RC Pillar is to test a prototypic commercially fabricated LEU fuel element, to determine whether any failure modes are observed or predicted in the fuel element, including significant deformations such as plate bending, twisting, or plate detachment from the side plate under selected safety-basis limits for reactor hydraulic conditions.

To support the conceptual design of the flow test for the hydraulic performance evaluation, design parameters for hydraulic testing of the LEU fuel element are laid out in this report. These relate to design needs of the reactor and are, therefore, referred to as reactor design parameters since they do not take into account design margins required for the experimental test design and other purposes. The flow rate per element is calculated using the flow network approach (balancing pressure drop for various channels within each element of the core) to provide the target test value of inlet conditions for the flow test and support computational fluid dynamics simulations. Note that the flow rate per element mentioned throughout this report has been increased to account for the additional flow area from the combined end channel gap.

The fuel element geometry, in particular the fuel plate and the flow channel dimensions are reviewed and documented. The key dimension for the flow test is the combined end channel (two end channels facing each other) gap thickness, which is related to the maximum hydraulic pressure differential acting on fuel plates. Both the nominal and the conservative dimensions of the combined channel are determined based on the technical drawings of the MITR fuel element. The normal operation conditions of the proposed MITR LEU core, including the coolant temperature, system pressure, and the coolant chemistry specification, are summarized to reference operation conditions for the planned flow tests and simulations.

To ensure the flow distribution and the pressure differentials acting on the plate for the flow test is similar to the prototypic in-pile conditions, the flow rate per element is calculated using the flow network method based on MITR core configurations, including both the transition core with 22 proposed LEU fuel elements and the equilibrium core with 24 proposed LEU fuel elements. For the 22-element core, the flow rate per element for the flow test was calculated to be $123.4 \mathrm{gpm}$, while for the 24-element core, this value is $113.3 \mathrm{gpm}$, based on a nominal total primary coolant flow rate of $2400 \mathrm{gpm}$. These values of flow rate per element do not include uncertainties in the flow distribution as well as the total flow rate. Thus, they can be considered as the best estimate values using flow network approach. Subsequently, detailed uncertainty analyses are performed, including the estimation of the upper bound of the flow rate per element, evaluation of flow distribution deviation between the flow test and the prototypic LEU core, and the quantification of the effects of potential

Massachusetts Institute of Technology Reactor LEU Fuel Element Flow Test Conceptual Design - Hydraulic Reactor Design Parameters 
operation temperature deviation and the flow channel gap thickness tolerances. An uncertainty factor of 1.2 is suggested to get the bounding value of flow rate per element from the best estimate value mentioned above, consistent with the factor used in the previous flow tests conducted for MITRII. For the temperature effect, if the flow test operating temperature is higher than that of MITR, the pressure differential acting on the plate could reduce slightly due to the lower coolant density at high temperature, and the effect of elevated temperature on the velocity distribution is insignificant, assuming that the same inlet volumetric flow rate is used. Furthermore, coolant channel gap thickness tolerances result in additional uncertainty of $8 \%$ in the pressure differential acting on the most limiting plate.

In summary, two primary design parameters relevant to the hydraulic performance evaluation of MITR LEU fuel element are provided in this report. First is the geometry of the flow channel, specifically, the combined end channel gap thickness, which determines the maximum channel size disparity and is related to the maximum hydraulic force (induced by pressure differential) on the fuel plate. The combined end channel gap thickness is 0.141 inch for nominal value and 0.247 inch for conservative value due to fabrication and assembly tolerances. The second important design parameter is the flow rate per element that has been increased to account for the additional flow area from the combined end channel gap. After this adjustment, the 22-element core flow rate per element value is $123.4 \mathrm{gpm}$, and the 24 -element core flow rate per element value is $113.3 \mathrm{gpm}$. This work provides information that will be used as a part of the design process for hydraulic evaluation, including flow testing a prototypic commercially fabricated LEU fuel element, and will be revised as needed. 


\section{Table of Contents}

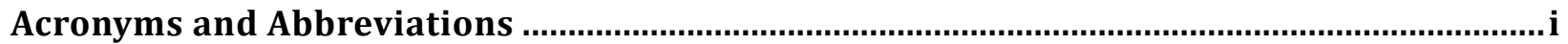

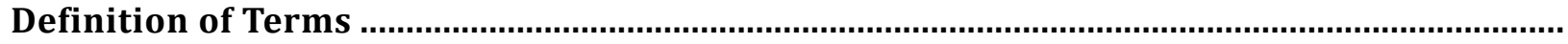

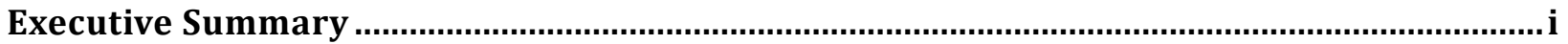

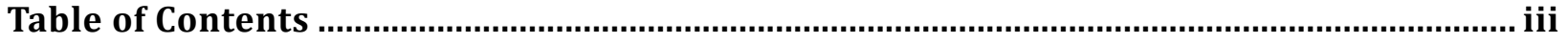

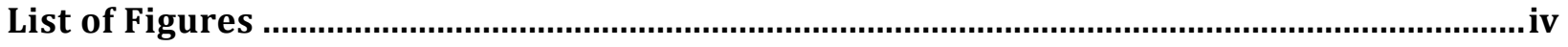

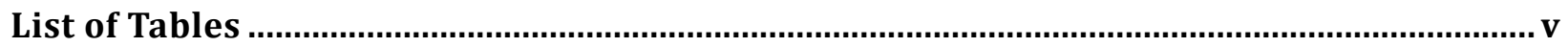

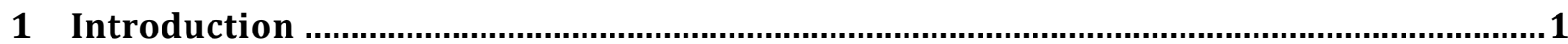

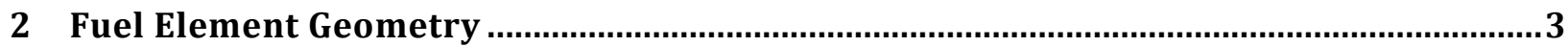

2.1 MITR LEU fuel element.......................................................................................................... 3

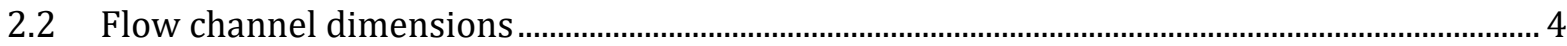

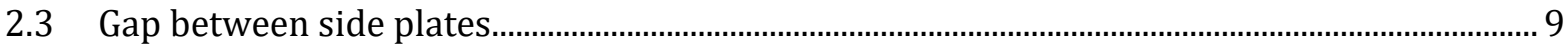

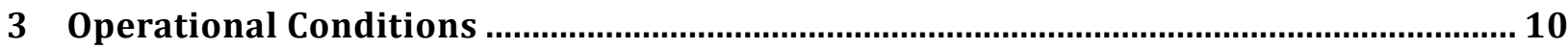

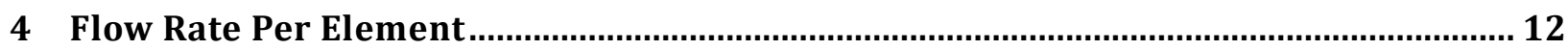

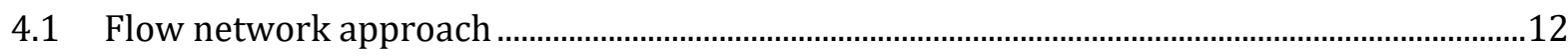

4.2 Transition core with 22 fuel elements .........................................................................................13

4.3 Equilibrium core with 24 fuel elements .....................................................................................14

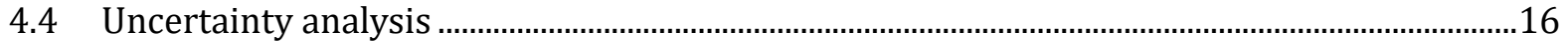

4.4.1 Flow rate upper limit.........................................................................................................

4.4.2 Flow distribution within one element.............................................................................17

4.4.3 Potential temperature effect ..................................................................................................

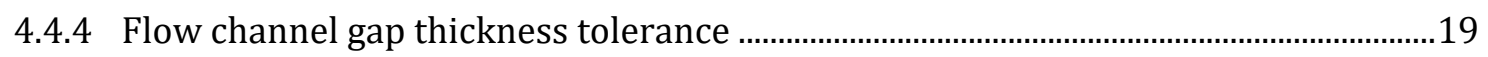

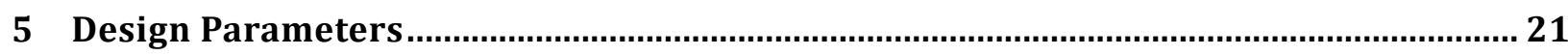

6 Summary

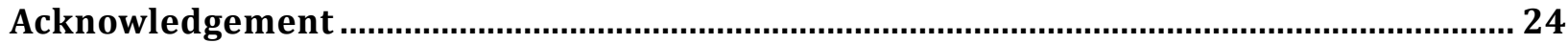

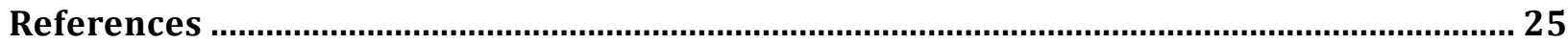

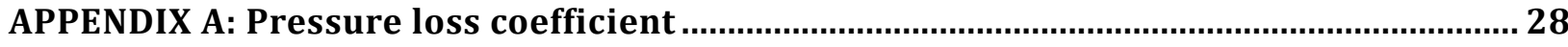

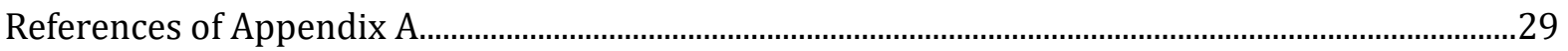




\section{List of Figures}

Figure 2.1. MITR core top view (left) and schematic cross-sectional view (right) [5] ............................ 3

Figure 2.2. MITR LEU fuel element perspective view .......................................................................................... 4

Figure 2.3. Schematic of MITR LEU fuel element cross-section ..................................................................... 4

Figure 2.4. Layout of the MITR reactor core (a) and end channels of element in various core positions (b) 5

Figure 2.5. Schematic of calculating nominal combined end-channel thickness ....................................... 6

Figure 2.6. MITR LEU element width and end channel dimension from drawing [9]............................. 7

Figure 2.7. Schematic of calculating conservative (without lift) combined end-channel size................. 7

Figure 2.8. Schematic (top view) of calculating conservative (with lift) combined end-channel size. 8

Figure 2.9. MITR LEU element end fitting dimensions [11] ..................................................................... 9 


\section{List of Tables}

Table 2.1. Channel types and nominal dimensions for the MITR LEU core ................................................. 5

Table 3.1. MITR LEU operation design parameters .............................................................................................11

Table 4.1. Channel types and quantities for the MITR fresh LEU core\# 1 at the startup phase.............13

Table 4.2 Flow rate per element for 22-element MITR LEU reactor core ...................................................14

Table 4.3. Channel types and quantities for the MITR core configuration \# 220 ……...............................15

Table 4.4. Flow rate per element for 24-element core …...............................................................................15

Table 4.5. Effect of fuel element orientation on flow network output......................................................16

Table 4.6. Summary of the nominal and conservative flow rate per element .........................................16

Table 4.7. Comparison of velocity and normalized pressure difference for one-element model and fullcore model at MITR prototypic operating conditions ….........................................................................

Table 4.8. Effect of coolant temperature on velocity distribution and pressure difference....................18

Table 4.9. Flow channel gap thickness tolerance effect on velocity and pressure differential $(\Delta p)$ predicted using one-element flow network for 24-element core ..................................................................19

Table 4.10. Flow channel gap thickness tolerance effect on velocity and pressure differential $(\Delta p)$ predicted using one-element flow network for 22-element core..................................................................20

Table 5.1. MITR LEU hydraulic reactor design parameters for flow test......................................................21 


\section{Introduction}

The Massachusetts Institute of Technology Reactor (MITR-II, also referred to as MITR), located in Cambridge, Massachusetts, is a research reactor designed primarily for experiments using neutron beams and in-core irradiation facilities. Its original version, MITR-I, was a heavy-water moderated and cooled research reactor. After a reevaluation of the utilization needs and further core optimization studies, it underwent a major upgrade and the current reactor design, MITR-II, began operation in 1976. The reactor is moderated and cooled by light water and uses heavy water as a reflector. The licensed power (thermal) of the MITR was uprated from $5 \mathrm{MW}$ to $6 \mathrm{MW}$ in 2011 in conjunction with the 20-year license renewal [1]. MITR delivers a neutron flux comparable to current LWR power reactors using highly enriched uranium (HEU) dispersion fuel enriched at $93 \mathrm{wt} \%{ }^{235} \mathrm{U}$.

MITR is one of six U.S. high performance research reactors (USHPRR), including one critical facility, that is actively collaborating with the National Nuclear Security Administration (NNSA) Material Management and Minimization $\left(\mathrm{M}^{3}\right)$ Reactor Conversion Program to convert to the use of lowenriched uranium (LEU, $<20 \mathrm{wt} \%{ }^{235} \mathrm{U}$ ) fuel. A new type of LEU fuel with very high density based on an alloy of uranium and $10 \mathrm{wt} \%$ molybdenum (U-10Mo) is expected to allow the conversion to LEU of USHPRR [2] that have been found to be unable to be converted with previously qualified uranium silicide-aluminum $\left(\mathrm{U}_{3} \mathrm{Si}_{2}-\mathrm{Al}\right)$ dispersion fuel.

The MIT Nuclear Reactor Laboratory has been working with the USHPRR Reactor Conversion (RC) Pillar at Argonne National Laboratory (Argonne) to perform fuel element design and fuel cycle performance analyses, steady-state thermal hydraulics safety analyses, and accident safety analyses in preparation for the conversion of MITR and support a preliminary Safety Analysis Report (SAR) for conversion to LEU fuel [3]. A detailed description of the preliminary MITR LEU fuel design can be found in [3].

This work is performed in preparation for the flow test campaign that will be conducted by the USHPRR RC Pillar. The purpose of the hydraulic performance evaluation of the MITR LEU fuel element designed by the RC Pillar is to test a prototypic commercially fabricated LEU fuel element to determine whether any failure modes are observed or predicted in the fuel element, including significant deformations such as plate bending, twisting, or plate detachment from the side plate under selected safety-basis limits for reactor hydraulic conditions.

Fuel plate deflection can be induced during reactor operation by the hydrodynamic pressure differential caused by differences in the channel gap of surrounding coolant channels, turbulent fluctuations in the flow, or both. Large flow-induced deflections of fuel plate could lead to a reduction of coolant channel flow area, which may lead to overheating of fuel plates.

In the flow test, a single MITR LEU fuel element will be tested in the Hydro-Mechanical Fuel Testing Facility (HMFTF) at Oregon State University (OSU) to evaluate the hydro-mechanical stability of the fuel plates. HMFTF is a large-scale thermal-hydraulic separate-effects test facility operating in conformance with the American Society of Mechanical Engineers (ASME) Nuclear Quality Assurance (NQA-1) standard (ASME NQA-1b-2008 with 2009 Addenda) [4]. The facility allows for testing a wide range of fuel plates and their assemblies, provided that they fit into the 15 -foot-tall test section. The HMFTF facility was designed to envelop the flow and pressure operating conditions of all highperformance research reactors in the U.S. as well as those required for fuel qualification. The range of operation of the loop covers flow rates (per element) ranging from $100 \mathrm{gpm}$ to $1600 \mathrm{gpm}$ and pressures of up to $475 \mathrm{psi}$. The testing loop is rated to $600 \mathrm{psig}$ and $460^{\circ} \mathrm{F}$. The configuration of the loop allows for up- and down-flows through the test section.

Massachusetts Institute of Technology Reactor LEU Fuel Element Flow Test Conceptual Design - Hydraulic Reactor Design Parameters 
To support the conceptual design of the flow test for MITR LEU fuel element, design parameters for hydraulic testing of the LEU fuel element are laid out in this report. These relate to design needs of the reactor and, are therefore, referred to as reactor design parameters since they do not take into account design margins required for the experimental test design and other purposes. MITR design parameters including system pressure, coolant temperature, and total core flow rate will be listed to provide a reference for the flow test conceptual design. The coolant flow rate per element is estimated based on the flow network analysis, which will provide the target test value of the inlet condition for the flow test. Note that the flow rate per element mentioned throughout this report has been increased to account for the additional flow area from the combined end channel gap. 


\section{Fuel Element Geometry}

\subsection{MITR LEU fuel element}

The MITR uses rhomboid-shaped fuel elements. The 27 in-core positions for fuel elements and/or irradiation experiments are illustrated in Figure 2.1. These positions are divided into three concentric rings - the inner ring (A) with three, the middle ring (B) with nine, and the outer ring (C) with 15 rhomboid-shaped areas [5]. There are boron impregnated stainless steel control blades along the hexagonal sides of the core. The reactor core is surrounded by a heavy-water reflector from the side and the bottom, and more than $10 \mathrm{ft}$ of light water above the core region, which provide effective neuron shielding. Typically, 24 of the 27 positions are occupied by fuel elements and the other three are occupied by an in-core experimental facility or a solid aluminum dummy.
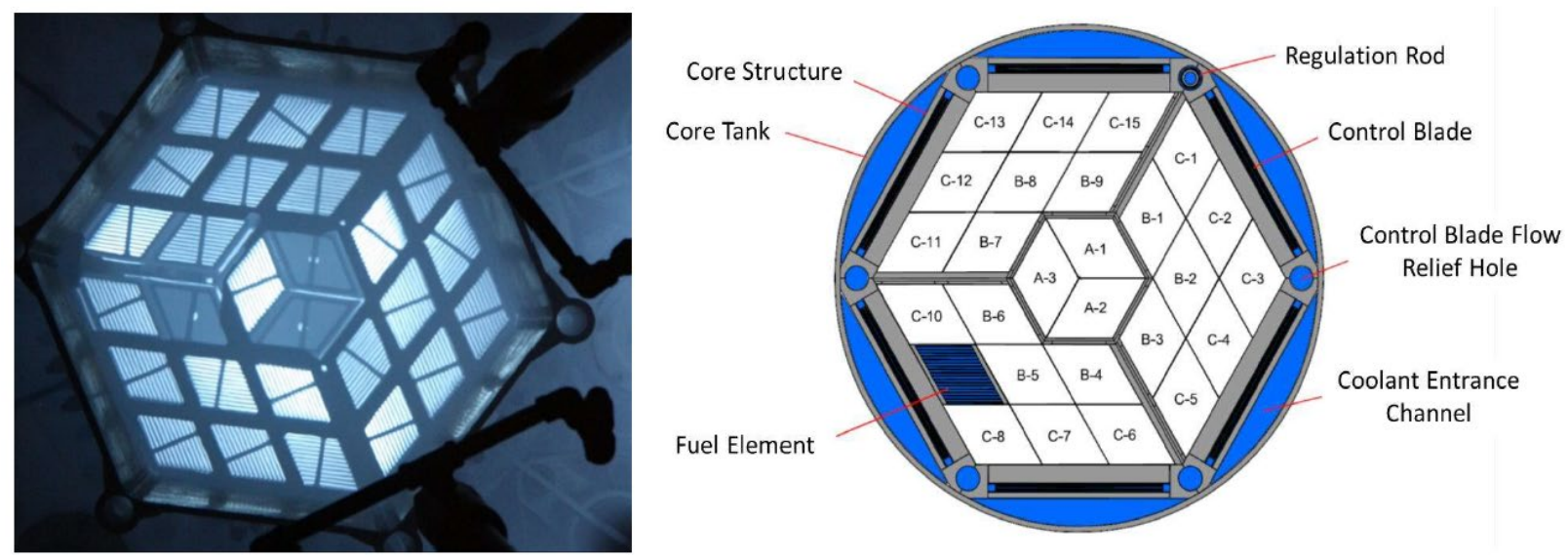

Figure 2.1. MITR core top view (left) and schematic cross-sectional view (right) [5]

The perspective view and cross-sectional view of the proposed LEU fuel element for MITR are shown in Figure 2.2 and Figure 2.3, respectively. Each LEU fuel element consists of 19 unfinned fuel plates with U-10Mo fuel core sandwiched between zirconium interlayers and encapsulated in aluminum cladding, two aluminum side-plates, and two end fittings. The fuel plates are assembled via swaging between two grooved side plates, which are 0.188 inch thick. The perpendicular distance between the side plate flats is $2.380 \mathrm{inch}$. The fuel plates are nominally 0.049 inch thick, 2.526 inch wide, 23.00 inch long and are spaced 0.0746 inch apart to form 182.308 inch-wide coolant channels [3]. Within an element, the spacing between the fuel plates is maintained by the grooves in the side plates. The end fittings are designed for handling and positioning the fuel element inside the reactor. The overall length of the element, including the end fittings, is $26.25 \mathrm{inch}$. Three types of fuel plates with the same total thickness ( $0.049 \mathrm{inch}$ ) but different fuel core thicknesses are used for each element to avoid the power peaking at the outer plates. As shown in Figure 2.3, T-plates (Plate No. 1 and 19) have a fuel core thickness of 0.013 inch (yellow color). Four Y-plates (Plate No. 2, 3, 17, and 18) have 0.017-inchthick core (orange color). Thirteen F-plates (Plates No. 4 - 16) have a fuel core thickness of 0.025 inch (red color). The fuel core is LEU enriched to $19.75 \mathrm{wt} \%{ }^{235} \mathrm{U}$ in the form of a U-10Mo monolithic alloy. The nominal thickness of aluminum alloy (AA6061) cladding is $0.017,0.015$, and 0.011 inch for T-, Y, and F-plates, respectively. The zirconium interlayers between fuel and cladding are nominally 0.001 inch thick. Detailed dimensions of the components of the proposed MITR LEU fuel element are available in the technical drawings $[6,7,8,9,10,11,12]$, and the major design parameters of the MITR LEU fuel are listed in Table 4-2 of [3]. 


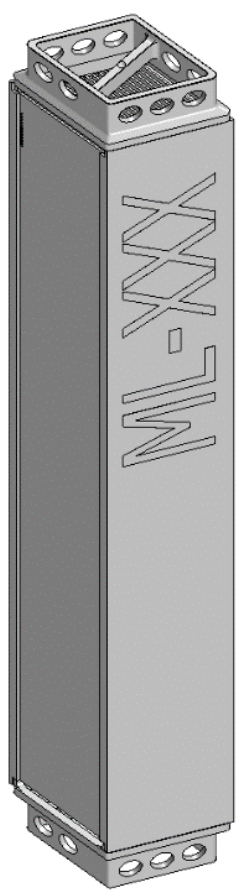

Figure 2.2. MITR LEU fuel element perspective view

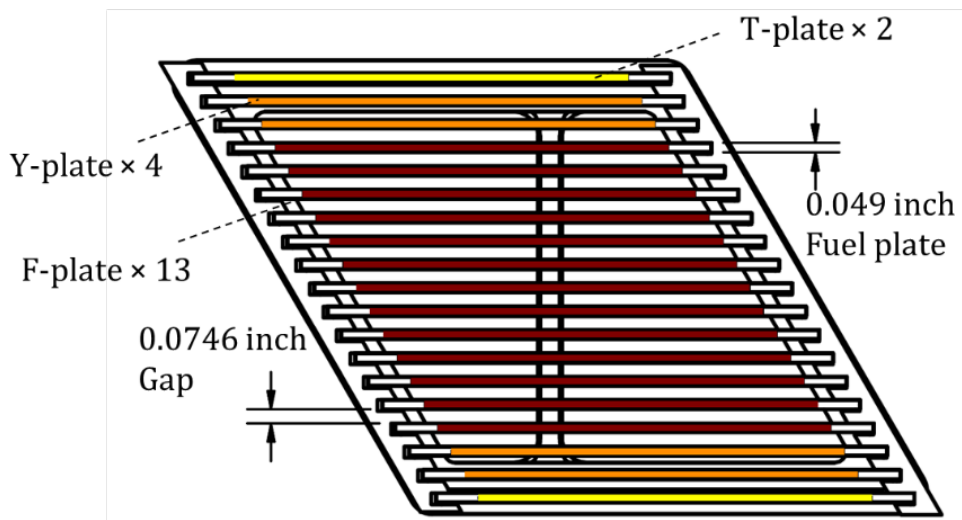

Figure 2.3. Schematic of MITR LEU fuel element cross-section

\subsection{Flow channel dimensions}

The 19 fuel plates of the proposed LEU fuel element form 18 internal flow channels with a nominal channel gap thickness of 0.0746 inch, as well as two end channels whose dimensions depend on the fuel element's position within the core and configuration of the neighboring elements. The deflection of the fuel plate occurs because of the pressure difference on the two sides of the plate, which usually results from the velocity disparity between two adjacent coolant channels of the plate. The velocity disparity is caused by the size difference between the two channels. Therefore, the most limiting plate in terms of hydro-mechanical stability of the MITR fuel element can be identified by comparing the size difference between two adjacent channels. Figure 2.4 shows the cross section of the MITR core with various types of end channels indicated. The end (outer) coolant channel of each element may face the core structure, a side plate, or an outer channel of a neighboring fuel element. The dimensions of the end channels shown in Figure 2.4 are listed in Table 2.1, which are calculated based on the technical drawings of MITR $[9,10,11,13,14]$. In the case where the outer channels of two 
neighboring elements face each other (two facing end channels, case (a) or (b) in Figure 2.4), they form a combined coolant channel with a nominal channel gap about twice the gap of an internal channel. These two types of fuel element positions and orientations result in the largest coolant channel size disparity in the MITR core and are referred to as a combined end channel throughout this report. Note that typical core configurations will not have two fuel elements in A-ring, as two of the three locations of A-ring are usually occupied by solid dummy elements. Therefore, the combined end channel is less likely to appear in A-ring.

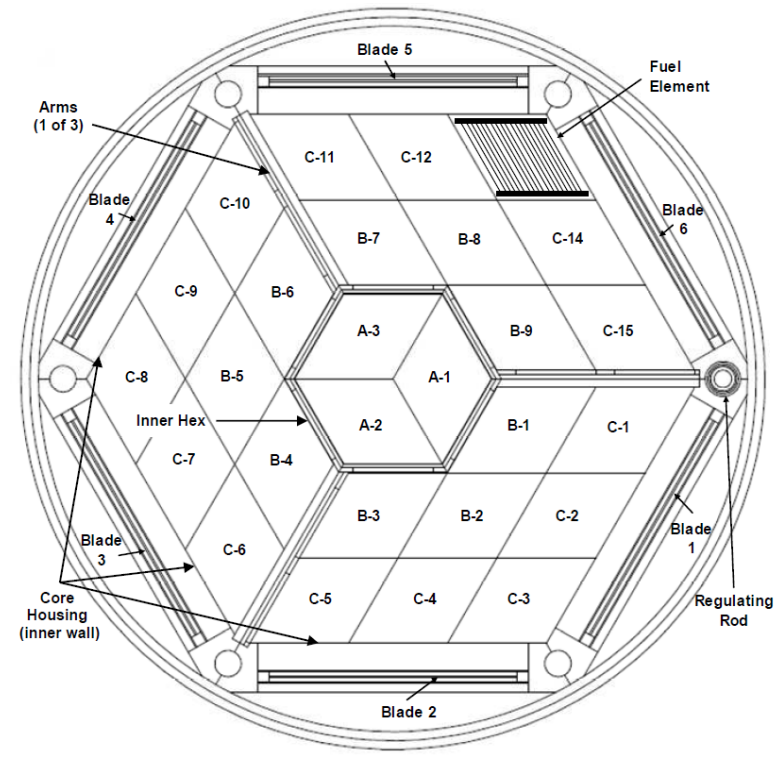

(a)

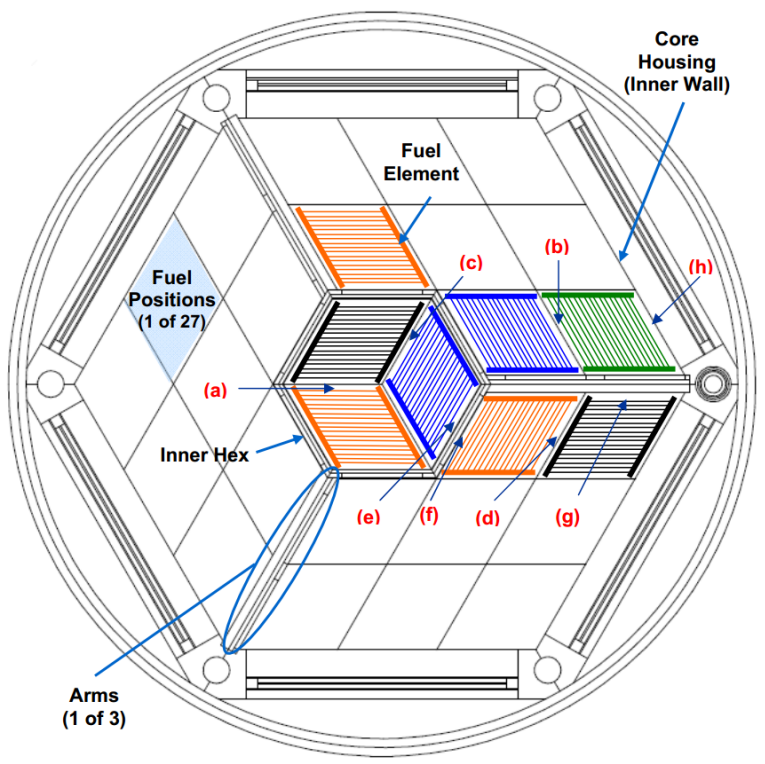

(b)

Figure 2.4. Layout of the MITR reactor core (a) and end channels of element in various core positions (b)

Table 2.1. Channel types and nominal dimensions for the MITR LEU core

\begin{tabular}{|c|l|c|}
\hline ID & \multicolumn{1}{|c|}{ Channel Configuration } & Channel Gap Thickness (inch) \\
\hline (a) & End channel facing adjacent-element end channel, A-ring & 0.1312 for 2 \\
\hline (b) & $\begin{array}{l}\text { End channel facing adjacent-element end channel, B/C } \\
\text { ring }\end{array}$ & 0.1412 for 2 $^{\mathrm{b}}$ \\
\hline (c) & End channel facing adjacent-element side plate, A-ring & 0.0791 \\
\hline (d) & End channel facing adjacent-element side plate, B/C-ring & 0.0891 \\
\hline (e) & End channel facing inner hex, A-ring & 0.0836 \\
\hline (f) & End channel facing inner hex, B-ring & 0.0826 \\
\hline (g) & End channel facing arm & 0.0706 \\
\hline (h) & End channel facing outer hex & 0.0806 \\
\hline (i) & Internal channel & 0.0746 \\
\hline
\end{tabular}

a Typical core configurations will not have two fuel elements in A-ring, as two of the three locations of A-ring are usually occupied by solid dummy elements. Therefore, the combined end channel is less likely to appear in A-ring.

${ }^{\mathrm{b}}$ Channel gap thickness for a combined end channel (two facing end channels). 
A single MITR LEU fuel element will be tested in HMFTF at OSU to evaluate the hydro-mechanical stability of the fuel plates. A test vehicle/basket is needed to accommodate the MITR LEU fuel element in the HMFTF test section. The conceptual design of the basket is currently being developed. Since only one element can fit to the basket, the outer channel will be formed between the element and the inner wall of the basket, and the dimension of the combined end channel will be considered in the basket design.

Given that the combined end channel gap thickness in B/C-ring ( 0.1412 inch) is larger than that in Aring ( $0.1312 \mathrm{inch})$, the end channel gap in $\mathrm{B} / \mathrm{C}$-ring is used in further considerations as the most limiting configuration. In addition, the combined end channel in A-ring is less likely to appear during the operation as two of the three locations of A-ring are usually occupied by solid dummy elements. Note that 0.1412 inch is the nominal value of the combined end channel; if considering the tolerance of the lower grid plate, end fitting, and the fuel plates, the combined end channel (two facing end channels) gap could be larger.

The schematic used for calculating the nominal width of the combined channel is shown in Figure 2.5. The nominal width of the combined end channel can be calculated as:

$$
2 \times 1.2075-2.405+2 \times 0.0656=0.1412 \text { (inch) }
$$

Where $1.2075 \mathrm{inch}$ is half of the sum of 2.145 and $0.270 \mathrm{inch}$, and the values of 2.145 and $0.270 \mathrm{inch}$ are the nominal lower grid opening size and the separation size (grey) between two adjacent openings, respectively [13]. As shown in Figure 2.6, the 2.405 inch is the element width defined by the size of the end fitting, and the 0.0656 inch is the distance from the outer surface of the outer plate (magenta) to the outer edge of the end fitting (light blue). Both values are taken from the MITR LEU element drawing [9]. Details from that drawing are shown in Figure 2.6. It is also assumed that both elements are fully seated and centered in the lower grid openings.

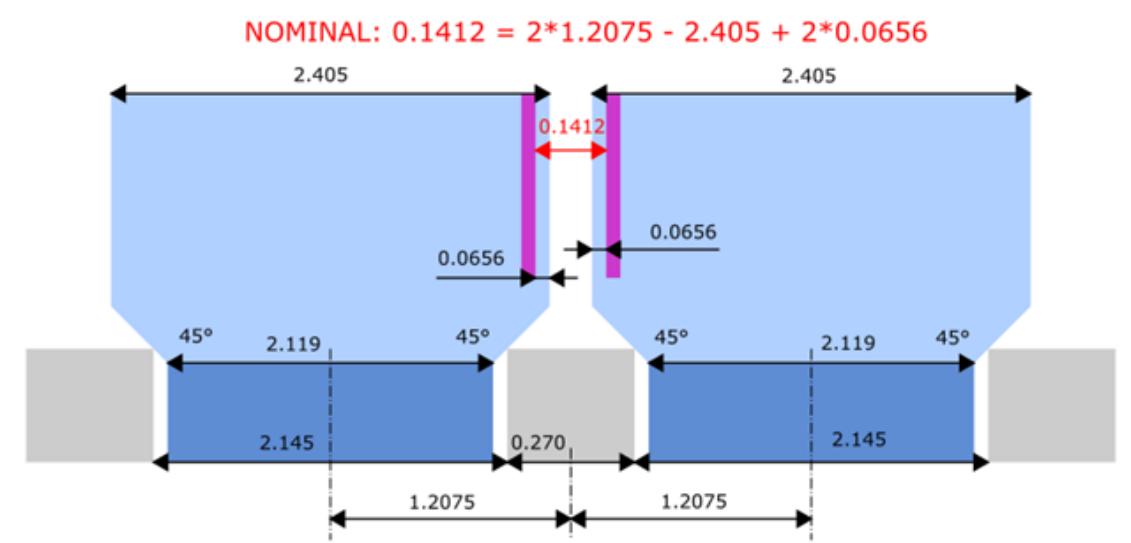

Figure 2.5. Schematic of calculating nominal combined end-channel thickness 

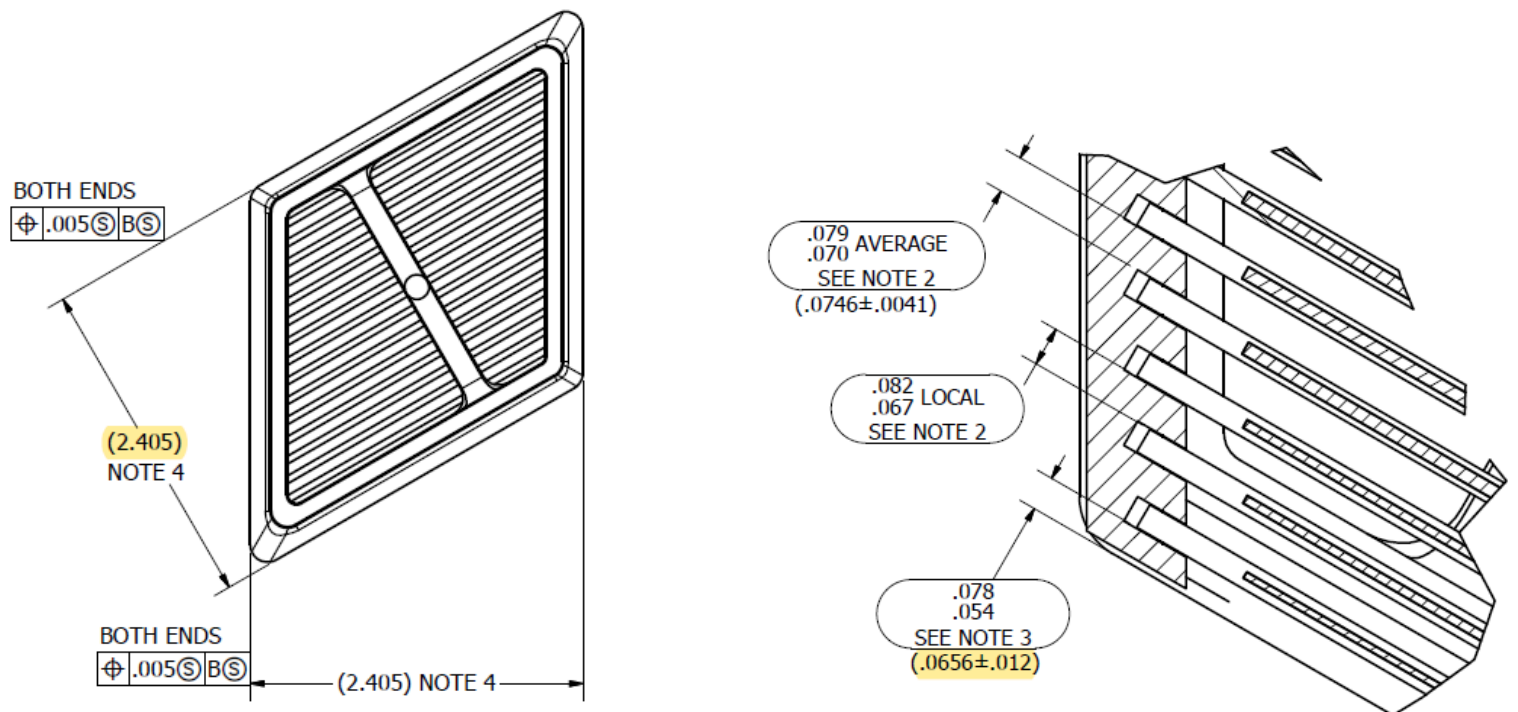

Figure 2.6. MITR LEU element width and end channel dimension from drawing [9]

For the conservative dimension of the combined end channel, as schematically shown in Figure 2.7, the calculation is:

$$
2 \times 1.2125-2.395+2 \times 0.078=0.186 \text { (inch) }
$$

The nominal values of 2.145 and 0.270 inch for the lower grid opening size and separation size increase 0.005 inch to account for the tolerance of the lower grid plate $[13,15]$, thus its maximum values are 2.15 and 0.275 inch, respectively, which leads to the value of 1.2125 in Figure 2.7. The nominal element width of 2.405 inch reduces to 2.395 inch by considering the 0.005 -inch dimension tolerance on both sides (see Figure 2.6). The end channel gap thickness (excluding gap between elements) change from the nominal value of 0.0656 inch to 0.078 inch, given the tolerance shown in Figure 2.6. Using these updated values, considering the tolerances of lower grid, end fitting width, and end channel gap, the distance between two facing end plates is 0.186 inch.

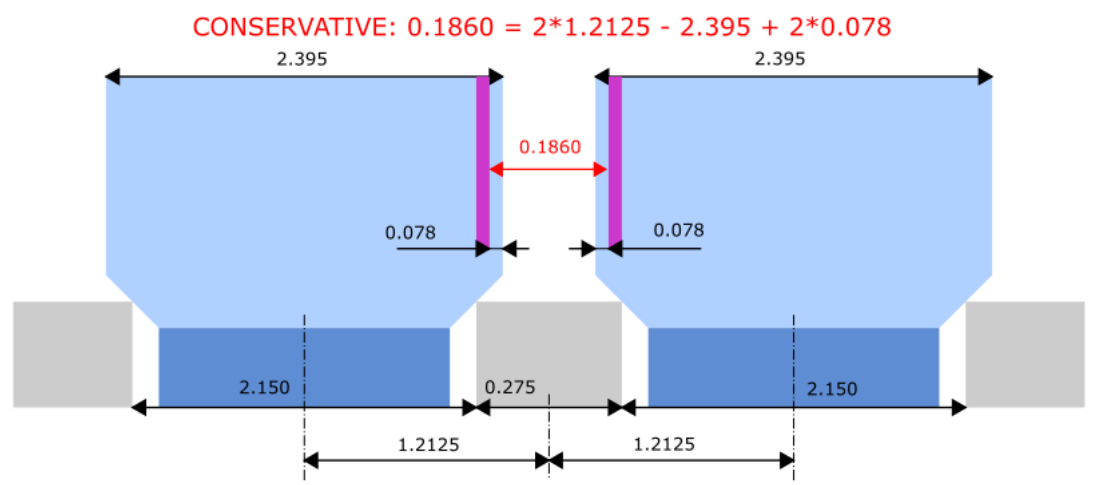

Figure 2.7. Schematic of calculating conservative (without lift) combined end-channel size

Note that the conservative dimension of 0.186 inch considers the manufacturing tolerances of the lower plate and the fuel element and also two elements fully seated and perfectly centered in the lower grid openings. Given the upward flow direction of MITR, if the fuel element is lifted by the flow, the fuel element may not be in the center of the lower grid opening. If taking the off-center related 
tolerances into account, the maximum combined end channel dimension could be as high as 0.247 inch, which is calculated from:

$$
0.275+2 \times 2.150-2 \times(2.395-0.153-0.078)=0.247 \text { (inch) }
$$

As mentioned above, the 2.150 inch and 0.275 inch is the maximum lower grid opening size and the maximum separation size between two adjacent openings, respectively. The $2.395 \mathrm{inch}$ and 0.078 inch is the minimum fuel element width and the maximum end channel gap thickness (excluding the gap between the elements). The 0.153 inch is the distance from the narrow part of the end fitting (dark blue part in Figure 2.7 and Figure 2.8) to the outer surface of the wide part of the end fitting (light blue part in Figure 2.7 and Figure 2.8) in the horizontal direction. The value of 0.153 inch is determined based on the nominal value of 0.143 inch and the 0.010 -inch tolerance from the technical drawing of the end fitting [11], which is presented in Figure 2.9.

The 0.247 inch is 0.061 inch larger than the conservative value of 0.186 inch for two adjacent elements concentrically seated in the lower grid openings, which means that there is an off-center displacement of 0.0305 inch for each of the two lifted elements. Note that the chamfer of the end fitting is $45^{\circ} \pm 1^{\circ}$. Therefore, the lift-up/float displacement of the fuel element should be equal to or larger than 0.0305 inch to allow the off-center displacement to reach the maximum value of 0.0305 inch in the horizontal direction. The clearance available for the element to float is 0.03125 inch $(1 / 32$ \pm 0.015 inch), which is calculated based on the core housing assembly drawing (R3S-3-5) [16] and the fuel element assembly drawing (R3F-201-4) [17]. Also, the force balance calculation performed in the previous work [18] indicates that the MITR LEU fuel element could be lifted by the coolant flow. Therefore, the maximum combined end channel (two facing end channels) gap thickness of 0.247 inch is selected in this work as the conservative value. Note that the 0.247 inch of combined end channel gap thickness is very conservative by assuming that all tolerances accumulate in the adverse way, and the probability of forming a combined end channel with 0.247 inch in the MITR core is very low. In addition, the full core flow network analysis shows that the internal channel flow velocity/rate reduces only $0.7 \%$ if increasing the thickness of a combined end channel in the core from 0.141 to $0.247 \mathrm{inch}$, indicating that the effect of an end channel with such a conservative thickness ( $0.247 \mathrm{inch}$ ) on the flow rate (as well as cooling capability) of internal channels is negligible. This can be calculated from the velocity data in Table 4.2 of Wang, et al. [18].

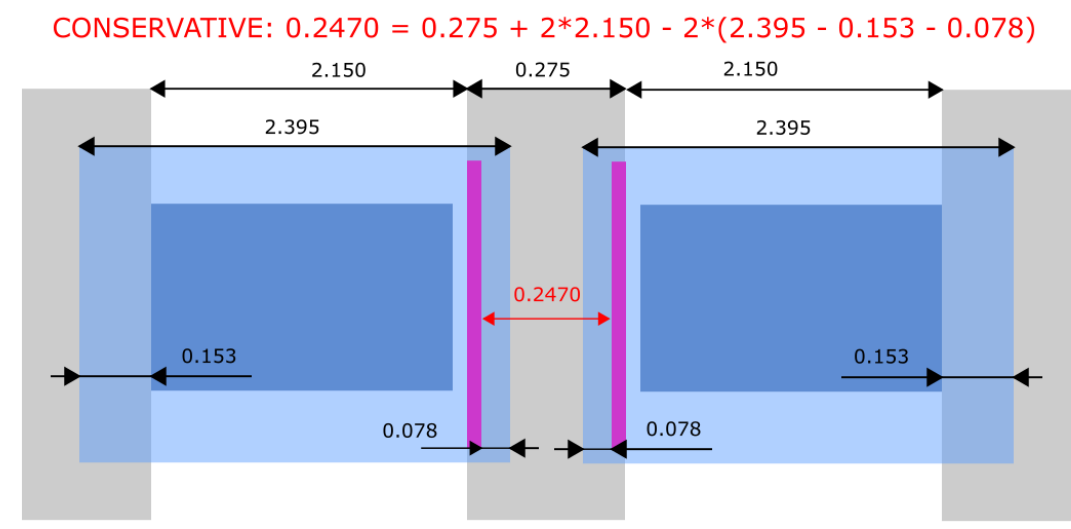

Figure 2.8. Schematic (top view) of calculating conservative (with lift) combined end-channel size 


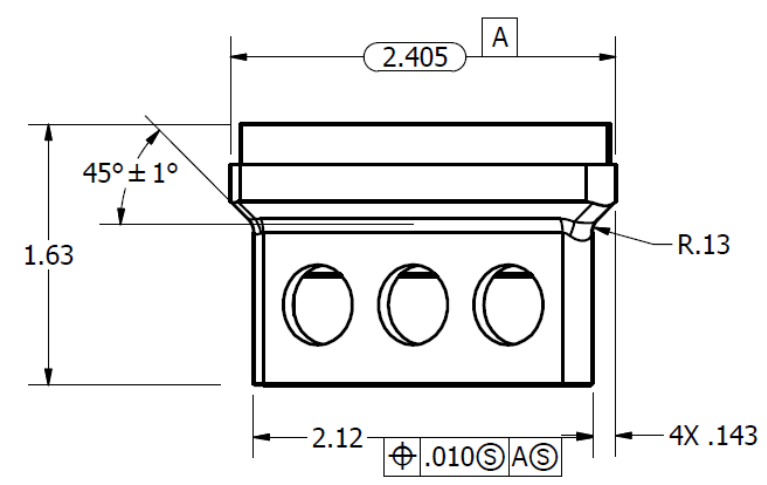

Figure 2.9. MITR LEU element end fitting dimensions [11]

\subsection{Gap between side plates}

The gap thickness between two adjacent elements with side plates facing each other (see channel " $\mathrm{x}$ " in Figure 2.4-b) is also calculated based on the technical drawings $[9,13]$ and will be used to guide the tolerances for the basket design.

Similar to the two facing end channels gap thickness calculation shown in Figure 2.5, the distance between two facing side plates can be calculated as:

$$
2.145+0.270-2.405=0.010(\text { inch })
$$

where the values of 2.145 and 0.270 inch are the nominal dimensions of the lower grid opening size and the separation size between openings, respectively [13]. The 2.405 inch is the element width defined by the end fitting dimension (Figure 2.6) from the MITR LEU element drawing [9]. Note that all these three numbers are the nominal values. If considering the default tolerance specified for the lower grid plate $[13,15]$, which is 0.005 inch for both, the grid opening size and the separation between two adjacent openings, as well as the element width tolerance of 0.005 inch on both sides (see Figure 2.6), the gap thickness of two facing side plates can be up to:

$$
2.150+0.275-2.395=0.030(\text { inch })
$$

Therefore, the distance between two facing side plates is 0.01 inch assuming nominal dimensions. If taking the tolerances of the lower grid opening and the element width into account, this value could be up to 0.03 inch. Note that both values are calculated assuming the element is fully seated (without lift). If the element is lifted by flow, the distance between two facing side plates could vary in a larger range. However, this distance has a negligible effect on the hydraulic stability of the fuel plates, so only the nominal value is relevant to the basket design.

Although using minimum possible gap thickness (instead of nominal value) between the side plates and the basket may help reduce the bypass flow through this gap and lead to a conservative flow rate in the channels, it is not suggested for basket design for three reasons: first, the basket is designed to minimize the bypass flow by only allowing the coolant flow through the end fitting (and not around it), and the effect of gap thickness between the side plates and the basket on bypass flow amount is negligible; secondly, using the nominal value (instead of minimum) of the distance between two facing side plates for basket design maintains a similar constraint configuration to the prototypic condition; thirdly, currently the assembly tolerances of the basket are not determined and too tight gaps around the element may cause element insertion interference.

Massachusetts Institute of Technology Reactor LEU Fuel Element Flow Test Conceptual Design - Hydraulic Reactor Design Parameters 


\section{Operational Conditions}

The preliminary LEU safety analysis [3], transition core planning and safety analysis [19], and the irradiation demonstration element design parameter [5] reports have been reviewed to collect the reactor design parameters relevant to the MITR LEU fuel element flow test. The results are summarized in Table 3.1.

MITR has upward coolant flow in the LEU reactor core, and the nominal flow rate is $2400 \mathrm{gpm}$, which will be used as a basis for the flow rate per element calculations in the next section. As mentioned in Section 2.2, the force balance calculation of MITR LEU element performed in the previous work [18] indicates that the fuel element could be lifted by the flow, which leads to the maximum combined end channel (two facing end channels) gap thickness of up to 0.247 inch, compared to the nominal value of $0.141 \mathrm{inch}$. The increased end channel gap thickness affects the flow distribution in the core as well as the flow rate per element of interest, which will be discussed in Section 4.

The pressure at the pump discharge is $17 \mathrm{psig}$, and at the top of the core outlet plenum is atmospheric. Note that the coolant level is 10 feet above top of the fuel plates [3], therefore at the core outlet, the pressure is 1.31 bar [20]. The nominal inlet and outlet coolant temperatures are $44{ }^{\circ} \mathrm{C}$ and $55^{\circ} \mathrm{C}$, respectively, while the maximum temperature inside the fuel plate at the fuel core center is $93.8{ }^{\circ} \mathrm{C}$. As mentioned in Section 1, the element is cooled with light water, with the chemistry specification provided in Table 3.1. The nominal reactor power for the operation with the LEU fuel is $7 \mathrm{MW}$, while the power at the limiting safety system setting (LSSS) is $8.68 \mathrm{MW}$. These hydraulic reactor design parameters, including pressure, temperature, and coolant chemistry information, provide a reference for the planned flow test conditions. 
Table 3.1. MITR LEU operation design parameters

\begin{tabular}{|c|c|c|}
\hline Parameter & Range & Reference \\
\hline $\begin{array}{l}\text { Flow rate } \\
\text { Minimum } \\
\text { Nominal } \\
\end{array}$ & $\begin{array}{l}2200 \mathrm{gpm} \\
2400 \mathrm{gpm}\end{array}$ & $\begin{array}{l}\text { MIT-NRL-18-01 Rev. } 2 \text { [3] } \\
\text { Table 5-1 }\end{array}$ \\
\hline $\begin{array}{l}\text { Inlet temperature } \\
\text { Nominal }\end{array}$ & $44^{\circ} \mathrm{C}$ & $\begin{array}{c}\text { MIT-NRL-18-03, Rev. } 2 \text { [5] } \\
\text { Table } 31\end{array}$ \\
\hline $\begin{array}{l}\text { Outlet temperature } \\
\text { Nominal } \\
\text { LSSS }\end{array}$ & $\begin{array}{l}55^{\circ} \mathrm{C} \\
60^{\circ} \mathrm{C}\end{array}$ & $\begin{array}{c}\text { MIT-NRL-18-02, Rev. } 1 \text { [19] } \\
\text { Table } 5\end{array}$ \\
\hline $\begin{array}{l}\text { Temperature increase } \\
\text { At Nominal Flow } \\
\text { At Minimum Flow }\end{array}$ & $\begin{array}{l}10^{\circ} \mathrm{C} \\
11^{\circ} \mathrm{C}\end{array}$ & $\begin{array}{l}\text { MIT-NRL-18-01 Rev. } 2 \text { [3] } \\
\text { Table 5-1 }\end{array}$ \\
\hline $\begin{array}{l}\text { Pressure } \\
\text { Pump Discharge } \\
\text { Top of Core Outlet Plenum }\end{array}$ & $\begin{array}{c}17 \text { psig } \\
\text { Atmospheric }\end{array}$ & $\begin{array}{l}\text { MIT-NRL-18-01 Rev. } 2 \text { [3] } \\
\text { Table 5-1 }\end{array}$ \\
\hline $\begin{array}{l}\text { Maximum temperaturea } \\
\text { Cladding Surface } \\
\text { Fuel Centerline }\end{array}$ & $\begin{array}{l}87.4^{\circ} \mathrm{C} \\
93.8^{\circ} \mathrm{C} \\
\end{array}$ & $\begin{array}{l}\text { MIT-NRL-18-03, Rev. } 2 \text { [5] } \\
\text { Table } 31\end{array}$ \\
\hline $\begin{array}{l}\text { Chemistry } \\
\text { pH } \\
\text { Conductivity } \\
\text { Chlorides }\end{array}$ & $\begin{aligned} & 5.5-7.5 \\
&< 5 \mu \mathrm{s} / \mathrm{cm} \\
&< 6 \mathrm{ppm} \\
&\end{aligned}$ & $\begin{array}{l}\text { MIT-NRL-18-01 Rev. } 2 \text { [3] } \\
\text { Table 5-1 }\end{array}$ \\
\hline $\begin{array}{l}\text { Reactor Power } \\
\text { Nominal } \\
\text { LSSS }\end{array}$ & $\begin{array}{c}7 \mathrm{MW} \\
8.68 \mathrm{MW}\end{array}$ & $\begin{array}{c}\text { MIT-NRL-18-02, Rev. } 1 \text { [19] } \\
\text { Table } 5\end{array}$ \\
\hline
\end{tabular}

a The maximum cladding surface and fuel centerline temperatures are equal to the maximum temperature on the cladding surface and in the fuel reached in the LEU element ML-136 during its residence time in the reactor core. The temperatures are local maxima from the fueled region divided into 16 axial and 4 lateral segments. 


\section{Flow Rate Per Element}

In the planned MITR LEU flow test, a single fuel element will be tested in HMFTF. It is critical that the flow test for one element is representative of the prototypic MITR operation condition. Therefore, the inlet flow rate for the flow test should be properly determined. In this section, the flow rate per element will be estimated based on a typical configuration of the core as well as the plate and coolant channel dimensions described in Section 2 and the operation condition summarized in Section 3. Note that the flow rate per element mentioned throughout this report has been increased to account for the additional flow area from the combined end channel gap.

\subsection{Flow network approach}

The flow network approach is used to estimate the flow rate per element, which is a method based on the conservation of mass and pressure-drop balance [18]. As shown in Table 2.1, there is a total of nine types of flow channels. Since the coolant density difference between inlet and outlet is less than $0.5 \%$ under nominal operating conditions, constant coolant temperature is assumed in the calculation, and the sum of flow rates in each type of channels should equal to the total core flow rate:

$$
\sum_{k=a}^{i} n_{k} Q_{k}=Q_{t o t}
$$

where $n_{k}$ is the number of channels of type $\mathrm{k}\left(k=a\right.$ to $i$, which is channel ID in Table 2.1), $Q_{k}$ represents the per channel volumetric flow rate of the channel type $k$, and $Q_{t o t}$ is the total volumetric flow rate of the core. Table 3.1 shows that the nominal primary flow rate is $2400 \mathrm{gpm}$. A portion of the coolant flows through a bypass that reduces the total flow by $7.9 \%$ [21]. A bypass factor of 0.921 was used in the previous MITR analyses [3] to account for the primary flow that bypasses fuel elements. This value was determined based on the previous measurements [21] of the core configuration MITR-II core II, which had five dummy elements and 22 fuel elements. The bypass flow was estimated by measurements and calculations, which are detailed in Table 4.6-2 of [21]. In addition, the bypass flow of configuration MITR-II core I with 24 fuel elements and 3 dummy elements was also measured, and the corresponding bypass factor was 0.949 . However, to maintain conservatism in the MITR thermal hydraulics analyses for LEU conversion [3, 19], the bypass factor of 0.921 was used for both the 22fuel-element and the 24-fuel-element cores. The bypass factor of 0.921 is used in this work to be consistent with the previous MITR LEU thermal hydraulics work $[3,19]$.

The pressure-drop balance can be expressed as:

$$
d p_{a}=d p_{b}=\cdots=d p_{i}
$$

$d p_{k}$ is the pressure drop in each of the type $k$ channel, which can be calculated using:

$$
d p_{k}=\frac{\rho v_{k}^{2}}{2}\left(K_{c}+K_{e}+\frac{f_{k} L}{D_{h, k}}\right)
$$

$v_{k}$ is the flow velocity, $\rho$ is the coolant density, and $K_{c}$ and $K_{e}$ are contraction and expansion pressure loss coefficients of the flow on the inlet and outlet, respectively. The values of $K_{c}$ and $K_{e}$ are 0.3 and 0.25 , which are estimated using the flow-area ratio of one fuel element and [22], as detailed in Appendix A. $L$ and $D_{h, k}$ are the length and hydraulic diameter of each type of the channel, respectively,

Massachusetts Institute of Technology Reactor LEU Fuel Element Flow Test Conceptual 
and $f_{k}$ is the friction factor. The friction factor is calculated using the explicit form [23] of the Colebrook-White equation [24]:

$$
f=\left\{-2 \log \left[\frac{\varepsilon}{3.7 D_{h}}+\frac{5.02}{R e} \log \left(\frac{\varepsilon}{3.7 D_{h}}+\frac{13}{R e}\right)\right]\right\}^{-2}
$$

The surface roughness $\varepsilon$ is assumed to be $0.001 \mathrm{~mm}$, which is a typical value for aluminum alloy [25]. With the known channel dimensions and number, the flow rate for each type of channel (i.e., internal channel, end/outer channel) can be calculated using Eq. (4.1) to (4.4), and the flow rate per element can be obtained by summing up the flow rate of corresponding channels.

\subsection{Transition core with 22 fuel elements}

For the proposed transition plan from HEU to LEU operation for MITR [19], the first cycle of the transition core is planned to host five dummy elements and 22 fuel elements, compared to the typical configuration of 24 fuel elements and three dummy elements. Since there is almost no coolant flow through the dummy element made of solid aluminum, the 22-element core is expected to have a higher flow rate per element than the 24-element core. Therefore, the transition 22-element core is more limiting from the perspective of the hydro-mechanical stability of fuel plates. The specific fuel orientation of the 22-element core is shown in Figure 4 of [19], from which the sum of each type of channels can be obtained; these numbers are listed in Table 4.1. For the end channel facing a dummy element, its thickness is assumed to be the same as the end channel facing a side plate of an adjacent element and counted as channel type (c) or (d). There are a total of 440 channels for the 22 fuel elements, as each element has 19 fuel plates and 20 flow channels. Note that the size of the end channels facing the end channels of adjacent elements ((a) and (b)) shown in Table 4.1 is for the combined channel; namely, 2 end channels with a thickness of 0.0705 inch (including gap between the elements) are combined to form a 0.141 inch channel. Table 4.1 shows that there are 12 combined end channels. The sizes of the other types of end channels ((c) to (h)) do not significantly differ from the nominal size of the internal channels (i).

Table 4.1. Channel types and quantities for the MITR fresh LEU core\# 1 at the startup phase

\begin{tabular}{|l|l|c|c|}
\hline ID & \multicolumn{1}{|c|}{ Channel Configuration } & Number & $\begin{array}{c}\text { Channel gap } \\
\text { thickness (inch) }\end{array}$ \\
\hline (a) & End channel facing adjacent-element end channel, A-ring & 0 & 0.1312 for 2 \\
\hline (b) & End channel facing adjacent-element end channel, B/C ring & 24 & 0.1412 for 2 \\
\hline (c) & End channel facing adjacent-element side plate, A-ring & 1 & 0.0791 \\
\hline (d) & End channel facing adjacent-element side plate, B/C-ring & 3 & 0.0891 \\
\hline (e) & End channel facing inner hex, A-ring & 1 & 0.0836 \\
\hline (f) & End channel facing inner hex, B-ring & 0 & 0.0826 \\
\hline (g) & End channel facing arm & 6 & 0.0706 \\
\hline (h) & End channel facing outer hex & 9 & 0.0806 \\
\hline (i) & Internal channel & 396 & 0.0746 \\
\hline
\end{tabular}

Using the number of channels and channel dimensions listed in Table 4.1, the channel width of 2.308 inch [3], the total flow rate of $2400 \mathrm{gpm}$, and the bypass factor of 0.921 , the flow rate for each type of channels can be calculated using flow network method discussed in Section 4.1. Then the flow rate 
per element $\left(Q_{e l e}\right)$, most likely in B/C-ring, can be obtained by summing up the flow rate of 18 internal channels (i), one combined end channel (b), and one end channel facing adjacent-element side plate:

$$
Q_{e l e}=Q_{b}+Q_{d}+18 \times Q_{i}
$$

Note that the 0.141 inch channel gap thickness of the combined end channel, in B/C-ring, is the nominal value. For the flow test, as discussed in Section 2.2, the conservative value of 0.247 inch of the end channel is expected to be used in the basket design. To estimate the flow rate of the element with a 0.247 inch end channel, the channel gap thickness of one combined end channel (b) is set to 0.247 inch in the flow network model, while the remaining 11 combined end channels are still 0.141 inch.

The flow rate per element calculated using the flow network is presented in Table 4.2. The thin end channel means that the channel type (d) with 0.088-inch channel gap thickness and the thick end channel is the combined end channel type (b) with the nominal channel gap thickness of 0.141 inch or the conservative value of 0.247 inch. For an element with the nominal thick end channel size, the flow rate is $108.1 \mathrm{gpm}$. For an element with the conservative thick end channel size of $0.247 \mathrm{inch}$, the flow rate is $123.4 \mathrm{gpm}$.

Therefore, if the flow test will be designed to simulate the element with two end channel gaps thickness of 0.247 inch and 0.088 inch, respectively, assuming the 22-element core with the 2400 gpm primary flow rate, the target test value of the inlet flow rate should be $123.4 \mathrm{gpm}$. This value does not include the uncertainties of flow distribution and the total flow rate, and it can be considered as the best estimate value using the flow network approach. The maximum/conservative value of inlet flow rate will be discussed in Section 4.4.

Table 4.2 Flow rate per element for 22-element MITR LEU reactor core

\begin{tabular}{|c|c|c|c|}
\hline Case & $\begin{array}{c}\text { Thin end } \\
\text { channel gap } \\
\text { thickness } \\
\text { (inch) }\end{array}$ & $\begin{array}{c}\text { Thick end } \\
\text { channel gap } \\
\text { thickness (inch) }\end{array}$ & $\begin{array}{c}\text { Flow rate per element } \\
\text { (gpm) }\end{array}$ \\
\hline Nominal end channel size & 0.088 & 0.141 & 108.1 \\
\hline Conservative end channel size & 0.088 & 0.247 & $\mathbf{1 2 3 . 4}$ \\
\hline
\end{tabular}

\subsection{Equilibrium core with 24 fuel elements}

Given that the MITR transition plan has not yet been finalized, the flow rate per element of the equilibrium core with 24 fuel elements (during normal operating conditions) is also analyzed using flow network to provide a range of possible inlet flow rates in the flow test. Since 24 fuel elements and three dummy elements is the typical MITR core configuration assuming normal operating conditions, there are many possible combinations of fuel element orientations and the number of each type of end channels can, therefore, vary. The fuel orientation configuration of HEU core \# 220 [26] is selected as a representative example. Since core configuration \# 220 is only one of the many possible sets of fuel orientation in the core, the evaluation of the effect of the fuel orientation on the flow network model output is also performed, which is presented in the later part of this section. Based on the fuel orientation of core \# 220, the number of each type of end channel are counted and listed in Table 4.3. 
Table 4.3. Channel types and quantities for the MITR core configuration \# 220

\begin{tabular}{|c|l|c|}
\hline ID & \multicolumn{1}{|c|}{ Channel Configuration } & Number \\
\hline (a) & End channel facing adjacent-element end channel, A-ring & 0 \\
\hline (b) & End channel facing adjacent-element end channel, B/C ring & 12 \\
\hline (c) & End channel facing adjacent-element side plate, A-ring & 1 \\
\hline (d) & End channel facing adjacent-element side plate, B/C-ring & 18 \\
\hline (e) & End channel facing inner hex (A-ring) & 1 \\
\hline (f) & End channel facing inner hex (B-ring) & 2 \\
\hline (g) & End channel facing arm & 6 \\
\hline (h) & End channel facing outer hex & 8 \\
\hline (i) & Internal channel & 432 \\
\hline
\end{tabular}

Using the channel number listed in Table 4.3, the bypass factor of 0.921 , and the total flow rate of $2400 \mathrm{gpm}$, the flow rate per element is calculated using the flow network method and listed in Table 4.4. If the flow test will be designed to simulate the element with end channels of 0.247 inch and 0.088 inch, assuming the 24 -element core with the 2400 gpm primary flow rate, the reference inlet flow rate should be $113.3 \mathrm{gpm}$. This value does not include the uncertainties of flow distribution and the total flow rate, and it can be considered as the best estimate value using the flow network approach. The maximum/conservative value will be discussed in Section 4.4

Table 4.4. Flow rate per element for 24-element core

\begin{tabular}{|c|c|c|c|}
\hline Case & $\begin{array}{c}\text { Thin end channel } \\
\text { gap thickness } \\
\text { (inch) }\end{array}$ & $\begin{array}{c}\text { Thick end } \\
\text { channel gap } \\
\text { thickness (inch) }\end{array}$ & $\begin{array}{c}\text { Flow rate per } \\
\text { element (gpm) }\end{array}$ \\
\hline Nominal end channel size & 0.088 & 0.141 & 99.1 \\
\hline Conservative end channel size & 0.088 & 0.247 & $\mathbf{1 1 3 . 3}$ \\
\hline
\end{tabular}

Since core configuration \# 220 is only one of the many possible core configurations, it is preferable to evaluate the effect of the orientation of the fuel element on the flow network model output. The fuel element configuration in A and B rings are fixed [19] and only C ring could have various types of fuel orientation for different core conditions. The input to the flow network is the number of each type of end channel, and different fuel element configurations could lead to the same number of each type of end channel. The end channel numbers of all possible fuel element configurations in C-ring $\left(2^{15}\right)$ are counted by automatic script, which leads to 251 combinations of end channel numbers to be used as the flow network input. The results using all 251 types of end channel combinations in the flow network are summarized in Table 4.5. The difference between the maximum and minimum flow rate per element for various fuel element orientations is less than $1 \%$, and the average flow for all fuel element orientations is very close to the flow rate per element for Core \# 220. Therefore, the effect of fuel elements' orientation in the core on the flow network output (flow rate per element) is negligible, and the flow rate calculated using the fuel orientation of Core \# 220 can be considered representative for the 24-element core. 
Table 4.5. Effect of fuel element orientation on flow network output

\begin{tabular}{|c|c|c|}
\hline \multirow{2}{*}{} & \multicolumn{2}{|c|}{ Flow rate per element (gpm) } \\
\cline { 2 - 3 } & $\begin{array}{c}\text { Nominal end channel gap } \\
\text { thickness }(0.141 \text { inch) }\end{array}$ & $\begin{array}{c}\text { Conservative end gap } \\
\text { thickness (0.247 inch) }\end{array}$ \\
\hline Maximum & 99.40 & 113.6 \\
\hline Minimum & 98.87 & 113.0 \\
\hline Average & 99.11 & 113.3 \\
\hline Core \# 220 & 99.11 & 113.3 \\
\hline
\end{tabular}

\subsection{Uncertainty analysis}

\subsubsection{Flow rate upper limit}

The flow rate per element of $123.4 \mathrm{gpm}$ for the 22-element core and $113.3 \mathrm{gpm}$ for the 24-element core are calculated using the primary coolant flow rate of $2400 \mathrm{gpm}$, the bypass factor of 0.921 , and the corresponding channel geometry specification. The flow rate per element could be higher if considering various uncertainties such as primary flow uncertainty and flow distribution uncertainty. In this section, the upper bounding limit of the flow rate per element is analyzed. The primary flow measurement uncertainty is 5\% [3]. The flow velocity distribution was measured with Pitot tubes for MITR-II, and the maximum flow rate per element is $12.1 \%$ higher than the average flow rate per element [21]. By multiplying the factor of $105 \%$ from the primary flow uncertainty by the factor of $112.1 \%$ associated with the flow distribution, the maximum flow rate is $117.7 \%$ of the nominal value. Note that these two uncertainties are conservatively considered here by multiplying instead of using square root error propagation formula. In the previous hydro-mechanical stability experiment for the MITR-II HEU fuel, a factor of $120 \%$ was used to represent the maximum possible flow rate [21], which provides another reference value for the upper limit of the per-element flow rate.

The summary of the nominal and conservative per-element flow rates for both the 22-element core and the 24-element core is provided in Table 4.6. The conservative values are calculated using the two options mentioned above: one is combining the $5 \%$ primary flow uncertainty and the $12.1 \%$ flow distribution uncertainty; the other is using $20 \%$ to represent all uncertainties. The second option with the $20 \%$ uncertainty is suggested here, because it is consistent with the previous MITR-II flow test and because it is more conservative. Therefore, the maximum inlet flow rate for the flow test is 148.1 gpm for the 22-element core and 135.9 gpm for the 24-element core.

Table 4.6. Summary of the nominal and conservative flow rate per element

\begin{tabular}{|c|c|c|c|c|}
\hline \multirow{2}{*}{ Core } & \multirow{2}{*}{$\begin{array}{c}\text { Thick end } \\
\text { channel gap } \\
\text { thickness } \\
\text { (inch) }\end{array}$} & \multicolumn{3}{|c|}{ Flow rate per element (gpm) } \\
\cline { 3 - 5 } & 0.141 & 108.1 & $\begin{array}{c}117.7 \% \text { of } \\
\text { nominal } \\
\text { value }\end{array}$ & $\begin{array}{c}120 \% \text { of } \\
\text { nominal } \\
\text { value }\end{array}$ \\
\hline \multirow{2}{*}{22 -element } & 0.247 & $\mathbf{1 2 3 . 4}$ & 127.2 & 129.7 \\
\cline { 2 - 5 } & 0.141 & 99.1 & 116.6 & 148.1 \\
\cline { 2 - 5 } & 0.247 & $\mathbf{1 1 3 . 3}$ & 133.4 & 13.9 \\
\hline
\end{tabular}




\subsubsection{Flow distribution within one element}

The hydraulic pressure differential, $\Delta p$, acting on a fuel plate can be estimated as:

$$
\Delta p=\frac{\rho}{2}\left(v_{1}^{2}-v_{2}^{2}\right)
$$

where $v_{1}$ and $v_{2}$ is the flow velocity of the two adjacent channels of the fuel plate, and $\rho$ is the coolant density. Since the hydraulic pressure differential $\Delta p$ is considered the primary reason for the fuel plate deformation, it is a parameter of interest for the flow test. It is expected to be as close to the prototypic condition as possible. The flow rate per element listed in Table 4.6 is calculated based on the full core flow network. If using this flow rate as the inlet condition for the flow test with one element, the velocity for each channel may be different from the velocity characteristic for the full core, and the pressure difference of the flow test could deviate from the prototypic condition. To evaluate the magnitude of the possible pressure differential between the flow test and the prototypic condition, the one-element flow network model is developed. The one-element flow network model only contains 18 internal channels (i), one thick end channel (b) with 0.247-inch channel gap thickness, and one thin end channel (d) to simulate the flow test. The calculated flow distribution of the one-element model is compared with the full-core flow network model in Table 4.7. Since the most limiting fuel plate of MITR LEU element is the outer-most one adjacent to the thick end channel (b) and an internal channel, the velocity of the thick end channel and the internal channel are listed, and the pressure difference $(\Delta p)$ is also calculated using Eq. (4.6) and normalized by the value of 24element flow network model. When setting the inlet flow rate of the one-element model as $113.3 \mathrm{gpm}$ to simulate the flow test of the 24-element core, the velocity of the two target channels as well as the pressure difference is almost identical to the 24-element model result with two digits accuracy. If setting the inlet flow rate of the one-element model as $123.4 \mathrm{gpm}$ to simulate the flow test of the 22element core, there is a slight deviation (less than 2\%) of the pressure difference and velocity.

In summary, the flow distribution calculated using the one-element flow network model is very close to that calculated using the full-core model, suggesting that the flow distribution deviation between the flow test and the prototypic condition could be insignificant. However, the limitation of the flow network method should be noted, since it simplifies the MITR LEU element geometry into parallel channels and considers averaged effects. Therefore, the velocities that are indicated as the same (or very close) for the one vs. 24-element cases would be expected to be somewhat different considering the effects of end fittings as well as some local effects on the flow distribution.

Table 4.7. Comparison of velocity and normalized pressure difference for one-element model and full-core model at MITR prototypic operating conditions

\begin{tabular}{|c|c|c|c|c|}
\hline $\begin{array}{c}\text { Flow network } \\
\text { model }\end{array}$ & $\begin{array}{c}\text { Inlet flow rate } \\
\text { (gpm) }\end{array}$ & $\begin{array}{c}\text { Internal channel } \\
\text { velocity }(\mathrm{m} / \mathrm{s})\end{array}$ & $\begin{array}{c}\text { Thick end channel } \\
\text { velocity (m/s) }\end{array}$ & $\begin{array}{c}\text { Normalized } \\
\Delta p(-)\end{array}$ \\
\hline 24-element & $2400(7.9 \%$ bypass) & 2.54 & 4.61 & 1.00 \\
\hline One-element & 113.3 (for 24 core) & 2.54 & 4.61 & 1.00 \\
\hline 22-element & $2400(7.9 \%$ bypass) & 2.77 & 5.03 & 1.19 \\
\hline One-element & 123.4 (for 22 core) & 2.77 & 5.01 & 1.18 \\
\hline
\end{tabular}

\subsubsection{Potential temperature effect}

Based on the communication between the Argonne SME and the OSU HMFTF SME, the OSU HMFTF operation temperature could have a lower limit of $120^{\circ} \mathrm{C}$, which is significantly higher than both the MITR inlet and outlet coolant temperatures $\left(44^{\circ} \mathrm{C}\right.$ and $55^{\circ} \mathrm{C}$, respectively [5] [19] ). It is suggested to enable HMFTF to operate at the MITR coolant temperature range by adjusting its operation or by modifying the facility. However, this is to be discussed with OSU and cannot be confirmed at this point,

Massachusetts Institute of Technology Reactor LEU Fuel Element Flow Test Conceptual Design - Hydraulic Reactor Design Parameters 
therefore, in this section, it is assumed that the flow test will be operated at $120^{\circ} \mathrm{C}$ and its implications to the parameter of interest will be analyzed.

The direct effect of elevated temperature for the flow test is the coolant density reduction. Water density under MITR outlet pressure (1.31 bar) at $44^{\circ} \mathrm{C}$ is $990.6 \mathrm{~kg} / \mathrm{m}^{3}$, which reduces to $943.1 \mathrm{~kg} / \mathrm{m}^{3}$ at $120^{\circ} \mathrm{C}$ under saturation pressure. Assuming the same flow velocity distribution, the decreased density leads to the plate pressure differential reduction by $4.8 \%$ (Eq. (4.6)). To evaluate the effect of reduced coolant density, the flow velocity distribution and pressure differential are calculated using the one-element model with the water density at $120^{\circ} \mathrm{C}$, which are compared with the fuel-core result at the prototypic coolant density listed in Table 4.8. Two options for the inlet flow rate of one-element model are analyzed, one is using the same volumetric flow rate as the prototypic one-element model (Table 4.7), the other is using the same mass flow rate, so the volumetric flow rate is increased to compensate the effect of the reduced coolant density. It is shown in Table 4.8 that reducing the coolant density by $4.8 \%$ but keeping the same volumetric inlet flow rate has a negligible effect on the calculated velocity, and the pressure difference decreases by around $4.8 \%$ due to the reduced density, according to Eq. (4.6). If using the same per element mass flow rate as the prototypic condition, the velocities for both the internal channel and the thick end channel increase due to the higher volumetric flow rate, and the pressure difference is also higher by $\sim \mathrm{x} \%$ than the full-core model. Although both options predict the pressure differential with $5 \%$ to $7 \%$ deviation, it is suggested to keep the volumetric flow rate for the flow test consistent with the prototypic per-element flow rate, instead of the mass flow rate. Because keeping the same volumetric flow rate resembles the velocity field of the prototypic conditions, and the deviation of pressure differential mostly comes from the reduced density at a higher temperature. The density deviation due to temperature differential is easy to quantify.

Table 4.8. Effect of coolant temperature on velocity distribution and pressure difference

\begin{tabular}{|l|c|c|c|c|}
\hline \multicolumn{1}{|c|}{ Flow network model } & $\begin{array}{c}\text { Inlet flow rate } \\
\text { (gpm) }\end{array}$ & $\begin{array}{c}\text { Internal } \\
\text { channel } \\
\text { velocity (m/s) }\end{array}$ & $\begin{array}{c}\text { Thick end } \\
\text { channel } \\
\text { velocity (m/s) }\end{array}$ & $\begin{array}{c}\text { Normalized } \\
\Delta p(-)\end{array}$ \\
\hline 24-element & $\begin{array}{c}2400 \\
(7.9 \% \text { bypass) }\end{array}$ & 2.54 & 4.61 & 1.00 \\
\hline $\begin{array}{l}\left.\text { One-element (at } 120^{\circ} \mathrm{C}\right) \\
\text { same volumetric flow rate }\end{array}$ & $\begin{array}{c}113.3 \\
\text { (for } 24 \text { core) }\end{array}$ & 2.54 & 4.62 & 0.96 \\
\hline $\begin{array}{l}\text { One-element (at } 120^{\circ} \mathrm{C} \text { ) } \\
\text { same mass flow rate }\end{array}$ & $\begin{array}{c}119.0 \\
\text { (for } 24 \text { core) }\end{array}$ & 2.67 & 4.84 & 1.05 \\
\hline 22-element & $\begin{array}{c}2400 \\
\text { (7.9\% bypass) }\end{array}$ & 2.77 & 5.03 & 1.13 \\
\hline $\begin{array}{l}\text { One-element (at } 120^{\circ} \mathrm{C} \text { ) } \\
\text { same volumetric flow rate }\end{array}$ & $\begin{array}{c}123.4 \\
\text { (for } 22 \text { core) }\end{array}$ & 2.77 & 5.02 & 1.23 \\
\hline $\begin{array}{l}\text { One-element (at } 120^{\circ} \mathrm{C} \text { ) } \\
\text { same mass flow rate }\end{array}$ & $\begin{array}{c}129.7 \\
\text { (for } 22 \text { core) }\end{array}$ & 2.91 & 5.26 & \\
\hline
\end{tabular}

In summary, if the flow test has to be performed at the coolant temperature of $120^{\circ} \mathrm{C}$, due to the reduced coolant density, the pressure differential on the two sides of the target fuel plate could be $5 \%$ lower than the pressure differential calculated for the prototypic conditions. However, the limitation of the flow network method should be noted, since it simplifies the MITR LEU geometry into parallel channels and considers averaged effects. Therefore, the velocities that are indicated as the same (or very close) for the one vs. 24-element cases would be expected to be somewhat different 
considering the effects of end fittings as well as some local effects on the flow distribution. Therefore, it is strongly suggested to operate the flow test at the prototypic temperature, which is $44{ }^{\circ} \mathrm{C}-55^{\circ} \mathrm{C}$.

\subsubsection{Flow channel gap thickness tolerance}

In the previous single-element flow network analysis, the ideal channel dimensions, namely the thick end channel gap thickness of $0.247 \mathrm{inch}$, the thin end channel thickness of $0.088 \mathrm{inch}$, and the internal channel thickness of 0.0746 inch, were used as the model inputs. In this section, the effect of the channel gap (thickness) tolerance is evaluated. Two types of tolerances are considered here: one is the end channel gap tolerance of 0.012 inch, the other is the internal channel gap tolerance of 0.0045 inch. Note that the 0.012 inch end channel gap tolerance is a preliminary conservative value and may be subject to change, since the fuel element basket design for the flow test has not been finalized yet. The end channel gap thickness tolerance is expected to be less than 0.012 inch. The 0.0045 inch internal channel gap tolerance is based on the technical drawing of the MITR LEU fuel element [9]. Note that the tolerance of 0.0045 inch is only considered for one internal channel adjacent to the limiting plate, while the rest 17 internal channels are assumed to be of the nominal size of $0.0746 \mathrm{inch}$. The results of calculations that consider the flow channel gap thickness tolerances for the 24-element core and 22-element core are listed in Table 4.9 and Table 4.10, respectively. The first row of each table is the result without considering the channel gap tolerance, which is gray shaded and has been presented in Table 4.7. The $2^{\text {nd }}$ and $3^{\text {rd }}$ row results consider the end channel dimension, the $4^{\text {th }}$ and $5^{\text {th }}$ row results consider the adjacent internal channel gap tolerance, and the $6^{\text {th }}$ and $7^{\text {th }}$ row results consider both tolerances. Table 4.9 and Table 4.10 show that the pressure differential could be $\pm 8 \%$ off if considering the 0.012 -inch end channel gap tolerance and 0.0045 inch internal channel gap tolerance.

Table 4.9. Flow channel gap thickness tolerance effect on velocity and pressure differential $(\Delta p)$ predicted using one-element flow network for 24-element core

\begin{tabular}{|c|c|c|c|c|c|}
\hline $\begin{array}{c}\text { Thick end } \\
\text { channel gap } \\
\text { (inch) }\end{array}$ & $\begin{array}{c}\text { Thin end } \\
\text { channel gap } \\
\text { (inch) }\end{array}$ & $\begin{array}{c}\text { Adjacent } \\
\text { internal } \\
\text { channel gap } \\
\text { (inch) }\end{array}$ & $\begin{array}{c}\text { Internal } \\
\text { channel } \\
\text { velocity (m/s) }\end{array}$ & $\begin{array}{c}\text { Thick end } \\
\text { channel } \\
\text { velocity } \\
\text { (m/s) }\end{array}$ & $\begin{array}{c}\text { Normalized } \\
\Delta p(-)\end{array}$ \\
\hline 0.247 & 0.0891 & 0.0746 & 2.54 & 4.61 & 1.00 \\
\hline $0.247+0.012$ & $0.0891-0.012$ & 0.0746 & 2.53 & 4.67 & 1.04 \\
\hline $0.247-0.012$ & $0.0891+0.012$ & 0.0746 & 2.55 & 4.54 & 0.95 \\
\hline 0.247 & 0.0891 & 0.079 & 2.62 & 4.59 & 0.96 \\
\hline 0.247 & 0.0891 & 0.070 & 2.45 & 4.63 & 1.04 \\
\hline $0.247+0.012$ & $0.0891-0.012$ & 0.070 & 2.44 & 4.69 & 1.08 \\
\hline $0.247-0.012$ & $0.0891+0.012$ & 0.079 & 2.63 & 4.53 & 0.92 \\
\hline
\end{tabular}


Table 4.10. Flow channel gap thickness tolerance effect on velocity and pressure differential $(\Delta p)$ predicted using one-element flow network for 22-element core

\begin{tabular}{|c|c|c|c|c|c|}
\hline $\begin{array}{c}\text { Thick end } \\
\text { channel gap } \\
\text { (inch) }\end{array}$ & $\begin{array}{c}\text { Thin end } \\
\text { channel gap } \\
\text { (inch) }\end{array}$ & $\begin{array}{c}\text { Adjacent } \\
\text { internal } \\
\text { channel gap } \\
\text { (inch) }\end{array}$ & $\begin{array}{c}\text { Internal } \\
\text { channel } \\
\text { velocity (m/s) }\end{array}$ & $\begin{array}{c}\text { Thick end } \\
\text { channel } \\
\text { velocity } \\
\text { (m/s) }\end{array}$ & $\begin{array}{c}\text { Normalized } \\
\Delta p(-)^{\mathrm{a}}\end{array}$ \\
\hline 0.247 & 0.0891 & 0.0746 & 2.77 & 5.01 & 1.18 \\
\hline $0.247+0.012$ & $0.0891-0.012$ & 0.0746 & 2.75 & 5.07 & 1.22 \\
\hline $0.247-0.012$ & $0.0891+0.012$ & 0.0746 & 2.78 & 4.93 & 1.12 \\
\hline 0.247 & 0.0891 & 0.079 & 2.85 & 4.99 & 1.13 \\
\hline 0.247 & 0.0891 & 0.070 & 2.67 & 5.03 & 1.22 \\
\hline $0.247+0.012$ & $0.0891-0.012$ & 0.070 & 2.66 & 5.09 & 1.27 \\
\hline $0.247-0.012$ & $0.0891+0.012$ & 0.079 & 2.87 & 4.92 & 1.08 \\
\hline
\end{tabular}

a $\Delta p$ listed is normalized using the 24-element core pressure difference, so the prototypic value is 1.19 (see Table 4.7) for 22-element core instead of 1.0. 


\section{Design Parameters}

The hydraulic design parameters for the MITR LEU fuel element are summarized in Table 5.1. The first design parameter is the combined end channel (end channels of two elements facing each other, see Table 2.1 for cases (b)) gap thickness, which determines the maximum channel size disparity, and the maximum hydraulic force (induced by pressure differential) on the fuel plate. The combined end channel gap thickness is 0.141 inch for nominal value and 0.247 inch for conservative value due to dimensional tolerances. For the flow test, although a single fuel element will be tested in HMFTF, the combined end channel dimension will be represented in the flow test through the basket design. The second design parameter is flow rate. The primary flow rate of the MITR LEU core is $2400 \mathrm{gpm}$, which is distributed into 22 or 24 fuel elements in the core, excluding the bypass flow of $7.9 \%$ through the unheated region. For the flow test of a single fuel element, the target test value of the inlet flow rate is calculated using the flow network analysis and $2400 \mathrm{gpm}$ core flow rate, which is $123.4 \mathrm{gpm}$ for the 22-element core and 113.3 gpm for the 24 -element core. Temperature influences target test value selection due to the impact of water density on the pressure differential in the test. However, temperature itself is not necessarily a primary design parameter. Until the capability of HMFTF to match the desired temperature range is clarified, water temperature is listed as regime appropriate. Other design parameters, including system pressure and coolant chemistry, are also listed as regime appropriate, but their influence on the flow test results is less significant.

The design parameters in this report, including MITR LEU channel dimensions and flow rate per element, provide the technical basis for the hydraulic performance evaluation including for the design of a dedicated flow test.

Table 5.1. MITR LEU hydraulic reactor design parameters for flow test

\begin{tabular}{|c|c|c|c|c|}
\hline $\begin{array}{c}\text { Design } \\
\text { parameters }\end{array}$ & Specification & Core condition & $\begin{array}{l}\text { Hydraulic } \\
\text { reactor design } \\
\text { parameter }\end{array}$ & Type \\
\hline \multirow{2}{*}{ Flow rate } & 22-element & $2400 \mathrm{gpm}$ & $123.4 \mathrm{gpm}^{\mathrm{c}}$ & \multirow{4}{*}{$\begin{array}{l}\text { Primary } \\
\text { design } \\
\text { parameter }\end{array}$} \\
\hline & 24-element & $2400 \mathrm{gpm}$ & $113.3 \mathrm{gpm}^{\mathrm{c}}$ & \\
\hline \multirow[b]{2}{*}{$\begin{array}{l}\text { Combined end } \\
\text { channel gap }\end{array}$} & Nominal & 0.141 inch & \multirow[b]{2}{*}{0.247 inch } & \\
\hline & $\begin{array}{c}\text { Conservative } \\
\text { within } \\
\text { tolerances }\end{array}$ & 0.247 inch & & \\
\hline Temperature $^{\mathrm{b}}$ & - & $44^{\circ} \mathrm{C}-55^{\circ} \mathrm{C}$ & - & \multirow{5}{*}{$\begin{array}{c}\text { Regime } \\
\text { appropriate }\end{array}$} \\
\hline System Pressured & - & Atmospheric & - & \\
\hline \multirow{3}{*}{ Chemistry } & $\mathrm{pH}$ & $5.5-7.5$ & - & \\
\hline & Conductivity & $<5 \mu \mathrm{s} / \mathrm{cm}$ & - & \\
\hline & Chlorides & $<6 \mathrm{ppm}$ & - & \\
\hline
\end{tabular}

a See Table 2.1 for cases (b).

$\mathrm{b}$ Temperature influences target test value selection due to the water density impact on the pressure differential in the test. However, it is not necessarily a primary design parameter. Until the capability of HMFTF to match the desired temperature range is clarified, temperature is listed as regime appropriate.

${ }^{c}$ The flow rate per element value was increased to account for the additional flow area from the combined end channel gap.

$\mathrm{d}$ The pressure at the top of the upper plenum is atmospheric. The coolant level is 10 feet above the top of the fuel plates [3], therefore at the core outlet the pressure is 1.31 bar [20]. 


\section{Summary}

This work is performed in preparation for the flow test campaign that will be conducted by the USHPRR RC Pillar. The purpose of the hydraulic performance evaluation of the MITR LEU fuel element designed by the RC Pillar is to test a prototypic commercially fabricated LEU fuel element, to determine whether any failure modes are observed or predicted in the fuel element, including significant deformations such as plate bending, twisting, or plate detachment from the side plate under selected safety-basis limits for reactor flow conditions.

Design parameters for hydraulic testing of the LEU fuel element are laid out on this report. These relate to design needs of the reactor and, are therefore, referred to as reactor design parameters since they do not take into account design margins required for the experimental test design and other purposes. Two primary design parameters are provided in this report. First is the geometry of the flow channel, especially the combined end channel gap thickness, which is related to the maximum hydraulic force (induced by pressure differential) on the fuel plate. Second is the flow rate per element, which is 123.4 gpm for the 22 -element-core and can be up to $20 \%$ higher if considering various uncertainties.

The fuel element geometry, including the fuel plate dimensions and the flow channel dimensions, are characterized. One key parameter for the flow test is the channel gap thickness of the combined end channel (two end channels facing each other), which is related to the maximum hydraulic force acting on the fuel plate. Both, the nominal ( $0.141 \mathrm{inch})$ and the conservative $(0.247$ inch with off-centered elements) thicknesses of the combined end channels gap are determined based on the technical drawings. The normal operational conditions of the MITR LEU core are summarized. The nominal coolant temperature at the inlet $\left(44^{\circ} \mathrm{C}\right)$ and outlet $\left(55^{\circ} \mathrm{C}\right)$, system pressure (atmospheric), and the coolant chemistry specification (conductivity, $\mathrm{pH}$, chlorides) will be used as the reference operation conditions for the conceptual design of the MITR LEU fuel element flow test.

The second primary design parameter is the flow rate per element, which is calculated using the flow network method. For the transition core with 22 fuel elements, the flow rate of the target element (with one 0.247 inch-thick outer channel) is $123.4 \mathrm{gpm}$. For the equilibrium core with 24 fuel elements, the flow rate of the target element (with one 0.247 inch-thick outer channel) is $113.3 \mathrm{gpm}$. Detailed uncertainty analyses are performed, including the conservative estimation of the flow rate per element, the evaluation of the flow distribution difference between the single element flow test and the proposed prototypic LEU core, and the quantification of the effects of potential operation temperature deviation and the flow channel dimension tolerances. The upper bounding value of the flow rate per element is obtained by multiplying the best estimate value mentioned above by an uncertainty value of 1.2. This value was chosen because the same uncertainty factor was used in the previous flow test conducted for MITR-II. For the effect of elevated temperature, the deviation of pressure differential mostly comes from the difference in coolant density, and the temperature effect on the velocity distribution is insignificant. If considering the channel gap dimensional tolerances (0.012 inch for the end channel and 0.0045 inch for the internal channel) for the flow test, the pressure differential between the two sides of the most limiting plate could be $\pm 8 \%$ of the value calculated using the nominal dimensions.

In summary, two primary design parameters relevant to the hydraulic performance evaluation of the MITR LEU fuel element are provided in this report. First is the geometry of the flow channel, specifically, the combined end channel gap thickness, which determines the maximum channel size disparity and is related to the maximum hydraulic force (induced by pressure differential) on the fuel

Massachusetts Institute of Technology Reactor LEU Fuel Element Flow Test Conceptual Design - Hydraulic Reactor Design Parameters 
plate. The combined end channel gap thickness is 0.141 inch nominally and 0.247 inch conservatively due to dimensional tolerances. Second is the flow rate per element that has been increased to account for the additional flow area from the combined end channel gap. After this adjustment, the 22element core flow rate per element value is $123.4 \mathrm{gpm}$, and the 24 -element core flow rate per element value is $113.3 \mathrm{gpm}$. The design parameters in this report, including MITR LEU channel dimensions and flow rate per element, provide the technical basis for the hydraulic performance evaluation, including the design of a dedicated flow test. 


\section{Acknowledgement}

The Massachusetts Institute of Technology Nuclear Reactor Laboratory is gratefully acknowledged for contributions to reactor conversion, including in formation of the works referenced. The authors would like to thank Dr. Son Pham and Dr. Walid Mohamed of Argonne National Laboratory for their valuable comments.

This work was sponsored by the U.S. Department of Energy, Office of Material Management and Minimization in the U.S. National Nuclear Security Administration Office of Defense Nuclear Nonproliferation under Contract DE-AC02-06CH11357. 


\section{References}

[1] MITR-Staff, "Safety Analysis Report for the MIT Research Reactor," MIT-NRL-11-01, Nuclear Reactor Laboratory, Massachusetts Institute of Technology, Cambridge, MA, 2011.

[2] E. Wilson, A. Bergeron, J. Stillman, T. Heltemes, D. Jaluvka and L. Jamison, "US high performance research reactor conversion program: An overview on element design," in Proc. European Research Reactor Conference, Rotterdam, Netherlands, May 14-18, 2017.

[3] K. Sun, L. W. Hu, E. H. Wilson, A. Bergeron and T. A. Heltemes, "Low Enriched Uranium (LEU) Conversion Preliminary Safety Analysis Report for the MIT Research Reactor (MITR)," MITNRL-18-01 Revison 2, Nuclear Reactor Laboratory, Massachusetts Institute of Technology, Cambridge, MA, 2018.

[4] "Quality Assurance Requirements for Nuclear Facility Applications," ASME NQA-1b-2008 with 2009 Addenda, American Society of Mechanical Engineers.

[5] K. Sun, A. Dave, L. W. Hu, D. Jaluvka, S. Pham, J. Stillman and E. Wilson, "Irradiation Demonstration Element Design Parameters for MITR LEU U-Mo Fuel Conversion," MITR-NRL18-03 Revision 2, Nuclear Reactor Laboratory, Massachusetts Institute of Technology, Cambridge, MA, 2020.

[6] R. Kmak, D. Jaluvka and E. Wilson, Type Y Fuel Plate, R4F-100-005-2, Massachusetts Institute of Technology Reactor, August 2018.

[7] R. Kmak, D. Jaluvka and E. Wilson, Type T Fuel Plate, R4F-100-006-2, Massachusetts Institute of Technology , August 2018.

[8] R. Kmak, D. Jaluvka and E. Wilson, Type F Fuel Plate, R4F-100-003-2, Massachusetts Institute of Technology Reactor, August 2018.

[9] R. Kmak, D. Jaluvka and E. Wilson, LEU Fuel Element, R4F-100-000-4, Massachusetts Institute of Technology Reactor, August 2018.

[10] R. Kmak, D. Jaluvka and E. Wilson, Side Plate, R4F-100-001-3, Massachusetts Institute of Technology Reactor (MITR), August 2018.

[11] R. Kmak, D. Jaluvka and E. Wilson, Nozzle end fitting upper R4F-100-002-3, Massachusetts Institute of Technology Reactor, August 2018.

[12] R. Kmak, D. Jaluvka and E. Wilson, Nozzle end fitting - lower R4F-100-004-3, Massachusetts Institute of Technology Reactor, August 2018. 
[13] Lower Grid Plate, M-79-22, Massachusetts Institute of Technology Reactor, October 1971.

[14] MITR Reactor MK-2 Core Housing Spider R35-12-2, Massachusetts Institute of Technology Reactor, 1974.

[15] E. Wilson, N. Horelik, F. Dunn, T. Newton Jr., L. W. Hu and J. Stevens, "Power distributions in fresh and depleted LEU and HEU cores of the MITR reactor," ANL/RERTR/TM-12-3, Revision 0, Argonne National Laboratory, Lemont, IL, February 2012.

[16] Core Housing Assembly Drawing, R3S-3-5, Revision 1, Massachusetts Institute of Technology, August 1970.

[17] Fuel Element Ass'y Drawing, R3F-201-4, Massachusetts Institute of Technology, February 1998.

[18] G. Wang, C. Bojanowski, D. Jaluvka, E. Wilson, L. W. Hu and A. Dave, "MITR Preliminary Design Verification - Preliminary Fluid-Structure Interaction Analysis," ANL/RTR/TM-21/2, Argonne National Laboratory, Lemont, IL, 2021.

[19] K. Sun, A. Dave, L. W. Hu, E. H. Wilson, D. Jaluvka, S. Pham and T. A. Heltemes, "Transitional Core Planning and Safety Analyses in Support of MITR LEU Fuel Conversion," MIT-NRL-18-02, Revision 1, Nuclear Reactor Laboratory, Massachusetts Institute of Technology, Cambridge, MA, 2020.

[20] A. J. Dave, K. Sun, L. W. Hu, S. H. Pham, E. H. Wilson and D. Jaluvka, "Thermal-hydraulic analyses of MIT reactor LEU transition cycles," Progress in Nuclear Energy, vol. 118, p. 103117, 2020.

[21] G. Allen Jr., L. Clark Jr., J. W. Gosnell and D. Lanning, "The reactor engineering of the MITR-II construction and startup," MITNE-186, Massachusetts Institute of Technology, Cambridge, MA, 1976.

[22] W. M. Kays and A. L. London, Compact Heat Exchangers, New York, NY: McGraw-Hill, 1984.

[23] D. Zigrang and N. Sylvester, "Explicit approximations to the solution of Colebrook's friction factor equation," AIChE Journal, vol. 28, no. 3, pp. 514-515, 1982.

[24] C. F. Colebrook and C. M. White, "Experiments with fluid friction in roughened pipes," Proceedings of the Royal Society of London. Series A-Mathematical and Physical Sciences, vol. 161, no. 906, pp. 367-381, 1937.

[25] R. Horváth and Á. Drégelyi-Kiss, "Analysis of surface roughness of aluminum alloys fine turned: United phenomenological models and multi-performance optimization," Measurement, no. 65, pp. 181-192, 2015. 
[26] MITR-Staff, PM 1.15 Core Configuration \#220, Nuclear Reactor Laboratory, Massachusetts Institute of Technology, Cambridge, MA, July 2016. 


\section{APPENDIX A: Pressure loss coefficient}

The pressure drop $\left(d p_{k}\right)$ of the type $k$ channel can be calculated using:

$$
d p_{k}=\frac{\rho v_{k}^{2}}{2}\left(K_{c}+K_{e}+\frac{f_{k} L}{D_{h, k}}\right)
$$

$v_{k}$ is the flow velocity and $K_{c}$ and $K_{e}$ are contraction and expansion pressure loss coefficients of the flow on the inlet and outlet, respectively. $K_{c}$ and $K_{e}$ are functions of the contraction and expansion geometry, and these coefficients have been established analytically for several simple entrance and exit geometries [A-1]. For the parallel-plate geometry, the solution is presented graphically in Fig. 53 of $[\mathrm{A}-1] . K_{c}$ and $K_{e}$ depends on the ratio between flow area to total area $(\sigma)$. Using the geometry dimension listed in the MITR LEU fuel element and side plate drawings [A-2, A-3] (as shown in Figure A.1), the total area can be calculated as:

$$
A_{\text {tot }}=2.38 \times \frac{2.378}{\cos \left(30^{\circ}\right)}=6.54\left(\mathrm{in}^{2}\right)
$$

and the flow area can be calculated as:

$$
A_{\text {flow }}=(2.38-0.049 \times 19) \times \frac{2.378-0.188 \times 2}{\cos \left(30^{\circ}\right)}=3.35\left(\mathrm{in}^{2}\right)
$$

Therefore, the ratio between flow area to total area is:

$$
\sigma=\frac{A_{\text {flow }}}{A_{\text {tot }}}=0.51
$$

Using the $\sigma$ of 0.51 and Fig. $5-3$ of [A-1], the $K_{c}$ and $K_{e}$ can be estimated to be 0.25 and 0.3 , respectively.
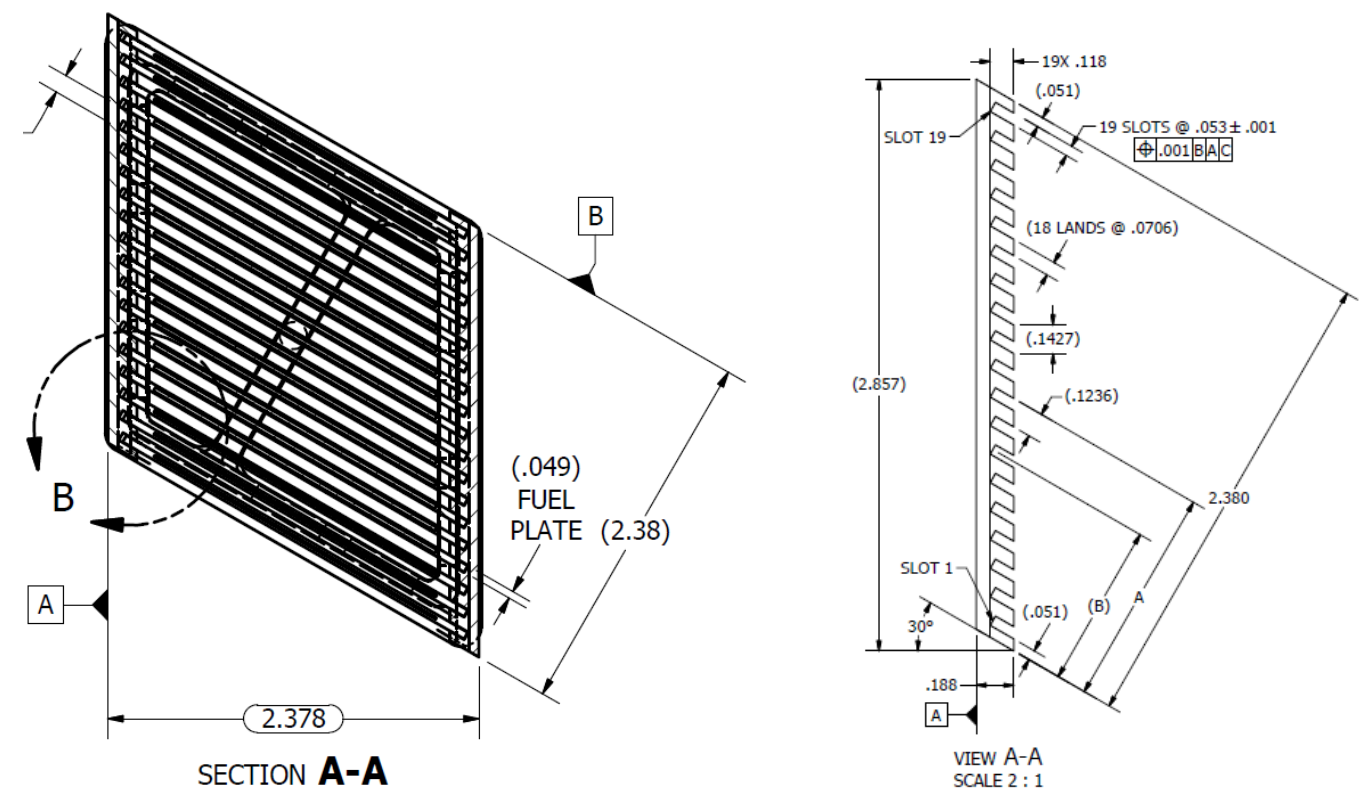

Figure A.1. MITR LEU fuel element dimension [A-2, A-3] 


\section{References of Appendix A}

A-1. W. M. Kays and A. L. London, Compact Heat Exchangers, New York, NY: McGraw-Hill, 1984.

A-2. R. Kmak, D. Jaluvka and E. Wilson, LEU Fuel Element, R4F-100-000-4, Massachusetts Institute of Technology Reactor, August 2018.

A-3. R. Kmak, D. Jaluvka and E. Wilson, Side Plate, R4F-100-001-3, Massachusetts Institute of Technology Reactor, August 2018. 


\section{Argonne $\mathbf{A}$}

Nuclear Science \& Engineering Division

Argonne National Laboratory

9700 South Cass Avenue, Bldg. 208

Argonne, IL 60439

www.anl.gov

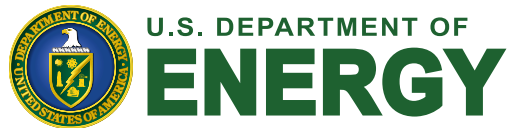

Argonne National Laboratory is a U.S. Department of Energy laboratory managed by UChicago Argonne, LLC 